\title{
Decadal changes of wintertime poleward heat and moisture transport associated with the amplified Arctic warming
}

\section{Xiaozhuo Sang}

Nanjing University

Xiu-Qun Yang ( $\sim$ xqyang@nju.edu.cn )

Nanjing University https://orcid.org/0000-0003-3716-9152

Lingfeng Tao

Nanjing University

Jiabei Fang

Nanjing University

Xuguang Sun

Nanjing University

\section{Research Article}

Keywords: Arctic amplification, poleward heat transport, poleward moisture transport, stationary wave, transient eddy

Posted Date: June 7th, 2021

DOI: https://doi.org/10.21203/rs.3.rs-264481/v1

License: (c) (1) This work is licensed under a Creative Commons Attribution 4.0 International License. Read Full License

Version of Record: A version of this preprint was published at Climate Dynamics on July 30th, 2021. See the published version at https://doi.org/10.1007/s00382-021-05894-7. 
1 Decadal changes of wintertime poleward heat and moisture transport

\section{associated with the amplified Arctic warming}

(1) Xiaozhuo Sang, Xiu-Qun Yang, Lingfeng Tao, Jiabei Fang, and Xuguang Sun

CMA-NJU Joint Laboratory for Climate Prediction Studies, School of Atmospheric

Sciences, Nanjing University, Nanjing, China

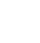

Corresponding author:

Dr. Xiu-Qun Yang,

School of Atmospheric Sciences,

Nanjing University, Nanjing 210023, China.

Email:xqyang@nju.edu.cn 


\section{Abstract}

The Arctic warming, especially during winter, has been almost twice as large as the global average since the late 1990s, which is known as the Arctic amplification. Yet linkage between the amplified Arctic warming and the midlatitude change is still under debate. This study examines the decadal changes of wintertime poleward heat and moisture transports between two 18-yr epochs (1999-2016 and 1981-1998) with five atmospheric reanalyses. It is found that the wintertime Arctic warming induces an amplification of the high latitude stationary wave component of zonal wavenumber one but a weakening of the wavenumber two. These stationary wave changes enhance poleward heat and moisture transports, which are conducive to further Arctic warming and moistening, acting as a positive feedback onto the Arctic warming. Meanwhile, the Arctic warming reduces atmospheric baroclinicity and thus weakens synoptic eddy activities in the high latitudes. The decreased transient eddy activities reduce poleward heat and moisture transports, which decrease the Arctic temperature and moisture, acting as a negative feedback onto the Arctic warming. The total poleward heat transport contributes little to the Arctic warming, since the increased poleward heat transport by stationary waves is nearly canceled by the decreased transport by transient eddies. However, the total poleward moisture transport increases over most areas of the high latitudes that is dominated by the increased transport by stationary waves, which provides a significant net positive feedback onto the Arctic warming and moistening. Such a poleward moisture transport feedback may be particularly crucial to the amplified Arctic warming during winter when the ice-albedo feedback vanishes.

Keywords: Arctic amplification; poleward heat transport; poleward moisture transport; stationary wave; transient eddy 


\section{Introduction}

The pronounced warming in the Arctic that is faster than the global average, known as the Arctic amplification (AA), has been observed during the past three decades (Graversen et al. 2008; Serreze et al. 2009; Cohen et al. 2014). Many studies suggested that sea ice decline is the primary cause of the observed AA due to the positive ice-albedo feedback (Screen and Simmonds 2010a; Dai et al. 2019). However, the greatest AA is found in the cold season when the solar radiation is low or even completely absent (Serreze and Francis 2006; Screen and Simmonds 2010b). Numerical experiments with atmospheric models showed that AA is still obvious with locked surface albedo (Alexeev et al. 2005; Graversen and Wang 2009), which suggest that surface albedo feedback is an important but not a dominating mechanism responsible for AA. The role of heat and moisture transports from outside the Arctic in AA was emphasized during winter when the shortwave radiation is negligible and the atmospheric boundary layer is stable (Zhang et al. 2013; Liu and Barnes 2015; Park et al. 2015b; Gong et al. 2017). It was found that, associated with anomalous large-scale circulations, poleward moisture fluxes into the Arctic lead to an increase in downward longwave radiation at the surface (Lee et al. 2011; Woods and Caballero 2016). Park et al. (2015a) showed that the positive trend of downward longwave radiation during winter accounts for as much as $50 \%$ of sea ice decline trend over the Arctic Atlantic sector.

Meanwhile, many observational and modeling studies suggested that the Northern Hemisphere $(\mathrm{NH})$ midlatitude mean flow and waves can be affected by AA even if there 
is a lot of controversies (Walsh 2014; Barnes and Screen 2015; Overland 2016; Vavrus 2018; Cohen et al. 2020). Cohen et al. (2014) proposed three potential dynamical pathways that may link the Arctic and the midlatitudes: jet stream, storm tracks, and planetary waves. Enhanced Arctic warming reduces the equator-to-pole temperature gradient at the surface, which causes the weakening of the midlatitude westerly winds (Coumou et al. 2015; Overland et al. 2015). A weak zonal jet could promote large amplitude and slowly-moving waves, which could create persistent weather conditions that may cause extreme weather events (Francis and Vavrus 2012; Liu et al. 2012; Screen and Simmonds 2014). Other studies questioned the validity of the above mechanisms, as they appear to be highly sensitive to the analysis metrics and datasets being used (Barnes 2013; Screen and Simmonds 2013). Generally, midlatitude atmospheric waves are characterized by transient eddies with zonal wavenumber typically larger than 5 and stationary waves with smaller wavenumbers as a response to diabatic and orographic forcing (Boer and Shepherd 1983; Petoukhov et al. 2013), the mechanisms of which are totally different. Previous studies did not distinguish the influence of AA on the stationary and transient waves in the midlatitudes. In this study, we will examine how the amplified Arctic warming can affect the stationary waves and transient eddies in the mid and high latitudes.

Stationary waves and transient eddies that may be affected by AA are the main agents for the atmospheric poleward transports of heat and moisture (Gimeno et al. 2015; Woods and Caballero 2016). Changes of these waves could cause changes in poleward transport, which may further have feedback onto AA. Previous studies 
focused on one-way impact but paid little attention to the midlatitude feedback. Therefore, there is a need to understand how the changes of these waves can further affect AA via altering poleward heat and moisture transports. In this study, we will examine the poleward transport changes associated with AA, which would help understand the linkage between the Arctic and the midlatitudes.

Graversen et al. (2008) found greater warming aloft than at the surface based on ERA-40 and concluded that the atmospheric poleward energy transport is the main driver of AA. In contrast, Screen and Simmonds (2010a) showed that the Arctic warming is the strongest at the surface based on the ERA-Interim reanalysis and mainly caused by the diminishing sea ice. This disagreement indicates discrepancy among different atmospheric reanalyses in the observational studies of AA. Atmospheric reanalysis provides a dynamically consistent view of the past state of the atmosphere by optimally combining historical atmospheric observations with numerical weather forecast model, which has uncertainties resulting from the forecast model, data assimilation, and data sources used. The spatially sparse and short observations in the high latitudes make the reanalysis in these areas more reliant on the forecast model, satellite data, and data assimilation methods. Thus, there are much greater uncertainties in the capability of reanalysis to provide atmospheric variables over the polar regions compared to other regions of the globe (Bromwich et al. 2007; Lindsay et al. 2014). Besides, many previous studies demonstrated that the reanalysis with coarse resolution forecast model generally underestimates the midlatitude synoptic eddy activity and eddy forcing on mean flow (Blender and Schubert 2000; Hodges et al. 2011; Tilinina et 
105

106

107

al. 2013). Thus, cautions are needed when analyzing the heat and moisture transports over mid and high latitudes related to transient eddies using reanalysis with coarse resolution forecast model.

The rest of the paper is organized as follows. Section 2 describes the atmospheric reanalysis datasets and the methods used. Section 3 presents the Arctic amplified warming and moistening, along with the decadal changes of poleward heat and moisture transports as the Arctic warms. The underlying mechanisms responsible for the influence of AA on the poleward transport changes are examined in section 4. Section 5 summarizes and discusses the possible feedback of mid and high latitude transport onto AA.

\section{Data and methods}

a. Atmospheric reanalysis datasets

In this study, daily variables are used which are taken from five atmospheric reanalyses (Table 1). One coarse-resolution reanalysis is NCEP-DOE R2 (NCEP2) (Kanamitsu et al. 2002). Four high-resolution reanalyses are ECMWF Interim ReAnalysis (ERA-Interim), 55-yr Japanese Reanalysis Project (JRA-55), NASA ModernEra Retrospective analysis for Research and Applications, Version 2 (MERRA-2), and NCEP Climate Forecast System Reanalysis (CFSR) (Saha et al. 2010; Dee et al. 2011; Harada et al. 2016; Gelaro et al. 2017). One of the improvements of these reanalyses is the increasing spatial resolution of forecast models from T62 ( 210km) in NCEP2 to T382 ( 38km) in CFSR. MERRA-2 generates with a finite volume model, which uses a cubed-sphere horizontal discretization at an approximate resolution of $0.5^{\circ} \times 0.625^{\circ}$ 
$(\sim 55 \mathrm{~km})$. These reanalyses also apply improved model physics and data assimilation systems. Both ERA-Interim and JRA-55 implement four-dimensional variational data assimilation (4D-Var) to include the observed temporal distribution within the assimilation window. The advanced data assimilation, model physics, and increase of resolution help to reduce the bias in reanalyses.

The horizontal resolutions of the reanalysis products used are $2.5^{\circ} \mathrm{x} 2.5^{\circ}$ (longitude/latitude) for NCEP2, $1.5^{\circ} \times 1.5^{\circ}$ for ERA-Interim, $1.25^{\circ} \times 1.25^{\circ}$ for JRA-55, $0.5^{\circ} \mathrm{x} 0.625^{\circ}$ for MERRA-2, and $0.5^{\circ} \mathrm{x} 0.5^{\circ}$ for CFSR. The physical variables of reanalysis used in this study include the wind velocity, geopotential height, air temperature, and specific humidity from 1000 to $200 \mathrm{hPa}$, with a focus on the troposphere. Note that NCEP2 does not provide specific humidity data; thus, we compute it from the relative humidity. The time span is from January 1980 to December 2017, with the convention that wintertime of 1980 refers to December of 1980, January and February of 1981.

\section{b. Decomposition of heat and moisture transports}

The poleward heat and moisture transports can be decomposed, respectively, as,

$$
\begin{aligned}
& {[\overline{v T}]=[\bar{v}][\bar{T}]+\left[\bar{v}^{*} \bar{T}^{*}\right]+\left[\overline{v^{\prime} T^{\prime}}\right]} \\
& {[\overline{v q}]=[\bar{v}][\bar{q}]+\left[\bar{v}^{*} \bar{q}^{*}\right]+\left[\overline{v^{\prime} q^{\prime}}\right]}
\end{aligned}
$$

where the brackets denote the zonal mean, the asterisks the departures from the zonal mean, the overbars the time mean, and the primes the departures from the time mean (Peixoto and Oort 1992). The term $[\bar{v}][\bar{T}]($ or $[\bar{v}][\bar{q}])$ in Eq. (1) or (2) represents the heat (or moisture) transport by the mean meridional circulation, which dominates in the 
tropics. The term $\left[\bar{v}^{*} \bar{T}^{*}\right]\left(\right.$ or $\left.\left[\bar{v}^{*} \bar{q}^{*}\right]\right)$ represents the poleward heat (or moisture) transport by stationary waves, and the term $\left[\overline{v^{\prime} T^{\prime}}\right]$ (or $\left[\overline{v^{\prime} q^{\prime}}\right]$ ) the poleward heat (or moisture) transport by the transient eddies. In this study, since the focus is on the changes of waves, the changes of total transport over mid and high latitudes mentioned below only signify those by stationary and transient waves.

The time- and zonal-mean local temperature (moisture) tendency induced by heat (moisture) transports of stationary waves or transient eddies is proportional to their convergences which can be expressed as,

$$
\begin{aligned}
& \frac{\partial[\bar{T}]}{\partial t} \propto-\frac{\partial\left[\bar{v}^{*} \bar{T}^{*}\right]}{\partial y}\left(\text { or }-\frac{\partial\left[\overline{\left.v^{\prime} T^{\prime}\right]}\right.}{\partial y}\right), \\
& \frac{\partial[\bar{q}]}{\partial t} \propto-\frac{\partial\left[\bar{v}^{*} \bar{q}^{*}\right]}{\partial y}\left(\text { or }-\frac{\partial\left[\bar{v}^{\prime} q^{\prime}\right]}{\partial y}\right) .
\end{aligned}
$$

Moreover, the heat or moisture transports by a stationary wave componet with zonal wavenumber $k$ can by expressed as,

$$
\begin{aligned}
& {\left[\bar{v}^{*} \bar{T}^{*}\right]_{k}=\left[\bar{v}_{k} \bar{T}_{k}\right],} \\
& {\left[\bar{v}^{*} \bar{q}^{*}\right]_{k}=\left[\bar{v}_{k} \bar{q}_{k}\right],}
\end{aligned}
$$

where $\bar{v}_{k}$ and $\bar{T}_{k}\left(\bar{q}_{k}\right)$ are the climatological meridional wind and temperature (moisture) disturbances, respectively, contributed only by stationary wave component with zonal wavenumber $k$, which are obtained by applying a Fourier transform.

\section{c. Eady growth rate}

According to linear baroclinic theories, the genesis of midlatitude transient eddies depends on the baroclinicity, which is proportional to the meridional temperature gradient divided by static stability (Eady 1949). The maximum Eady growth rate is calculated to measure the atmospheric baroclinicity, which is defined as 


$$
\sigma_{B I}=-0.31 \frac{g}{\theta N}\left|\frac{\partial \theta}{\partial y}\right|
$$

where $N$ denotes the Brunt-Väisäl $\ddot{a}$ frequency, $\theta$ the potential temperature, and $g$ the gravity acceleration (Lindzen and Farrell 1980; Hoskins and Valdes 1990).

\section{d. Regression analysis}

In this study, the decadal changes of wintertime poleward heat and moisture transports between two 18-yr epochs (1999-2016 and 1981-1998) associated with AA are firstly documented with five atmospheric reanalyses. To further confirm the impact of AA and its possible feedback, the relationship between the Arctic wanming and the midlatitude poleward transport is then examined on interannual time scale. The components of more than 8 years for all variables are removed. An Arctic warming index is defined as wintertime mean surface air temperature (SAT) averaged over $75^{\circ} \sim$ $90^{\circ} \mathrm{N}$ and $0^{\circ} \sim 360^{\circ}$. The poleward heat and moisture transports are regressed on the normalized Arctic warming index to study the linkage between the Arctic SAT and the poleward transport on interannual time scale.

\section{Changes in poleward heat and moisture transports}

\section{a. Observed Arctic warming and moistening}

Near-surface in the Northern Hemisphere high latitudes is warming during recent two decades at a double rate of lower latitudes and the global average, which can be seen from SAT changes across five reanalyses (The colored solid lines in Fig. 1). This observed phenomenon is known as the Arctic amplification (AA). AA occurs in all seasons, with the strongest in autumn and winter (Figs. 1i,1). Although the warming trends are not identical among the reanalyses, as shown from the spread (the range 
between minimum and maximum; shading in Fig. 1), the five reanalyses depict a consistent amplified warming trend since the late 1990s. All our analyses below are concentrated on the boreal winter (December, January, and February, DJF) when AA is the strongest and atmospheric poleward transport may play a vital role in AA due to the absent solar radiation in the Arctic (Park et al. 2015a). The amplified warming in high latitudes relative to the rest of the NH starts in the winter of 1998/99 (Figs. 1e,f). Therefore, we examine the epoch (decadal) differences of 18-yr mean SAT and any other variables between 1999/2000-2016/17 and 1981/82-1998/99 to represent atmospheric changes associated with AA. Note that the results can hold if the start year of AA is slightly changed.

Figure 2 demonstrates the decadal changes of SAT in five reanalyses. All reanalyses show an overall warming in the Arctic except over the Greenland-Labrador Sea in NCEP2 and MERRA-2. This warming is particularly pronounced over the Barents-Kara Sea. Furthermore, an additional warming can be seen over northeastern America and a cooling over Eurasian continents and North Pacific. Figure 3 shows the vertical structure of zonally averaged temperature and specific humidity changes. All the five reanalyses exhibit a significant Arctic warming throughout the troposphere, extending toward the midlatitude around $50^{\circ} \mathrm{N}$, with maximum warming located in the lower troposphere (left panels of Fig. 3). NCPE2 and JRA-55 depict a slightly weaker warming in the mid-troposphere north of $60^{\circ} \mathrm{N}$ than the other reanalyses. Meanwhile, the Arctic warming is accompanied by the Arctic moistening, as shown from significantly increased specific humidity over the Arctic region (right panels of Fig. 3). 
The Arctic moistening is confined in the lower troposphere below $700 \mathrm{hPa}$, with a slightly smaller magnitude in JRA-55 and a larger magnitude in NCEP2. Note that, due to lack of direct model output, the specific humidity in NCEP2 is derived from the relative humidity, which may yield bias.

\section{b. Decadal changes in poleward heat and moisture transports}

In this subsection, we examine the wintertime decadal changes in poleward heat and moisture transports associated with AA. The decadal changes in zonally averaged poleward heat transport in mid and high latitudes are shown in Fig. 4. Total heat transport changes (left panels of Fig. 4) from five reanalyses are contributed by stationary waves (middle panels of Fig. 4) and transient eddies (right panels of Fig. 4). Note that poleward transport change by the mean meridional circulation contributes little to the total heat transport changes in high latitudes. The climatological profiles of poleward heat and moisture transports by stationary waves and transient eddies are positive over the $\mathrm{NH}$ and peak in the midlatitudes, indicating that atmospheric waves transport heat and water vapor from the tropics to the Arctic (Peixoto and Oort 1992). As the Arctic warms, the poleward heat transport by stationary waves increases over most of regions north of $45^{\circ} \mathrm{N}$ except for the lower troposphere around $60^{\circ} \mathrm{N}$ (middle panels of Fig. 4), with the largest increase in the lower troposphere. The second maxima is located in the upper troposphere of the high latitudes and may be influenced by the stratosphere. On the other hand, the poleward heat transport by transient eddies significantly decreases in the mid-to-lower troposphere of the extratropics (right panels of Fig. 4). Thus, the increased poleward heat transport by stationary waves is mostly 
offset by the decreased poleward heat transport by transient eddies. Consequently, the total poleward heat transport change in the mid and high latitudes below $600 \mathrm{hPa}$ is minor (left panels of Fig. 4).

Similar to the heat transport, the zonally averaged poleward moisture transport by stationary waves also shows pronounced increases in the mid and high latitudes, especially at lower layers (middle panels of Fig. 5). NCEP2 shows a decrease of stationary moisture transport below $700 \mathrm{hPa}$ between $50^{\circ}$ and $65^{\circ} \mathrm{N}$, which differs from the other four reanalyses and may be related to the bias in specific humidity calculation. The moisture transport by transient eddies decreases in the low levels except for the near-surface of the Arctic and increases in the upper levels (right panels of Fig. 5). The total poleward moisture transport increases in the high latitudes (left panels of Fig. 5), which is dominated by the increased moisture transport by stationary waves. The increased poleward heat and moisture transports by stationary waves are located in the lower troposphere over from the Barents Sea to western America with the largest increase over the Barents Sea, while the poleward heat and moisture transports by transient eddies show an overall decrease in high latitudes.

\section{c. Local tendencies induced by poleward heat and moisture transport changes}

To get a better understanding of the contribution of the poleward heat and moisture transport changes to the Arctic warming and miostening, heat and moisture transport flux convergences by stationary waves and transient eddies are further diagnosed according to Eqs. (3) and (4), respectively. As shown in the middle panels of Fig. 6, the stationary heat flux convergence enhances over the region north of $75^{\circ} \mathrm{N}$, which 
corresponds to the maximum poleward stationary heat transport around $75^{\circ} \mathrm{N}$ (middle panels of Fig. 4). On the other hand, the transient eddy heat flux convergence shows an overall decrease north of $75^{\circ} \mathrm{N}$, which tends to induce a decrease in temperature in high latitudes (right panels of Fig. 6). The total heat flux convergence generally shows a cancellation between the stationary and transient heat flux convergences, which reveals little contribution of the total poleward heat transport to the Arctic warming.

The moisture flux convergence by stationary waves is similar to that of heat and is characterized by increases in the high latitudes, which tends to moisten the polar region (middle panels of Fig. 7). The moisture flux convergence by transient eddies decreases below $600 \mathrm{hPa}$ in mid and high latitudes and slightly increases above it, which is prone to play a negative feedback in the Arctic moistening (right panels of Fig. 7).

The total moisture flux converges over the polar region, which is dominated by the transport of stationary eddies and tends to amplify the Arctic moistening.

\section{d. Poleward transports associated with interannual Arctic warming}

In order to confirm the impact of AA on the high latitude poleward heat and moisture transports and their possible feedbacks onto the Arctic warming, which are investigated with decadal changes above, the interannual relationship between the Arctic wanming and the midlatitude poleward transport is examined below. The components of more than 8 years for all variables are removed. The interannual anomalies of the poleward heat and moistute transports and their convergences are regressed upon a normalized the Arctic warming index as described in Section $2 \mathrm{~d}$. The regression analysis is based on the CFSR dataset, since the new high-resolution 
reanalysis has made big improvements in resolving transient eddies (Hodges et al. 2011; Jung et al. 2012). On the interannual time scales, when winter Arctic SAT anomalies are positive, significant positive poleward heat and moisture transport anomalies by stationary waves are observed in the lower troposphere of the high latitudes, with the maximum located at $75^{\circ} \mathrm{N}$ (Figs. 8b,e), which induce increases in the tendency of Arctic temperature and moisture, respectively (Figs. 9b,e). Meanwhile, negative poleward heat and moisture transport anomalies by transient eddies occupy the lowertroposphere of the high latitudes (Figs. 8c,f) and cause the decrease in the tendency of Arctic temperature and moisture (Figs. 9c,f) except for the moisture over the Arctic near-surface. The results of increased transport by stationary waves and decreased transport by transient eddies are quite consistent with those from decadal differences (center and left panels of Figs. 4,5). The total poleward heat transport shows a weak and insignificant positive anomaly north of $75^{\circ} \mathrm{N}$ that is basically offset by stationary waves and transient eddies (Fig. 8a), which induces weak and insignificant temperature tendencies north of $80^{\circ} \mathrm{N}$ (Fig. 9a). The total moisture transport exhibits positive anomalies in the high latitudes with maxima located in the lower troposphere, which is dominated by the stationary component (Fig. 8d). The total moisture transport converges north of $75^{\circ} \mathrm{N}$, showing positive moisture tendencies in the Arctic (Fig. 9d). Therefore, on the interannual time scales, the total poleward heat transport shows cancellation between stationary and transient components, while the total poleward moisture transport increases as Arctic warms. This confirms the impact of AA on the high latitude poleward heat and moisture transports and their feedbacks onto the Arctic 
warming on the decadal time scales.

\section{Mechanisms for the poleward heat and moisture transport changes}

a. Mechanisms for stationary heat and moisture transport changes

Figures 10a-e show the decadal changes of 18-yr mean $500 \mathrm{hPa}$ geopotential height among five reanalyses. An increased geopotential height is centered in the Novaya Zemlya where the tropospheric warming is the most amplified and the sea ice loss is the most. The rise of $500 \mathrm{hPa}$ height over Novaya Zemlya weakens the trough over the northwestern Russia, as shown in black contours in the left panels of Fig. 10. Another increased geopotential height is found over the North Atlantic, with the center located in the southern Greenland. The increased geopotential height extends to the Arctic and tends to link up with that over the Novaya Zemlya. The decreased geopotential height extends from the Bering Strait to the Beaufort Sea, which weakens the climatological ridge. These changes are consistent among five reanalyses, with the maximum magnitude in NCEP2 and minimum in ERA-Interim. Both the increased height over Novaya Zemlya and Greenland and the decreased height over Chukchi Sea contribute to the transition of dominant stationary wave component from zonal wavenumber 2 before 1999/2000 to wavenumber 1 after 1999/2000, which are shown in contours in the left panels of Fig. 10.

To further identify the changes in stationary waves with different spatial scales, we decompose the $500 \mathrm{hPa}$ geopotential height into zonal wavenumber space. The results of the changes in amplitude of zonal wavenumber 1-6 are shown in the right panels of Fig. 10. The increase in the amplitude of wavenumber 1 and decrease in the 
amplitude of wavenumber 2 north of $55^{\circ} \mathrm{N}$ are found in all reanalyses. The amplitude changes of stationary waves with zonal wavenumber larger than 2 are much smaller, with a slight decrease of wavenumber 3 and a slight increase of wavenumber 4 in the mid and high latitudes. For the extratropical stationary waves forced by diabatic heating or orography, the heating is balanced by meridional temperature advection from a dry dynamical perspective (Hoskins and Karoly 1981; Held et al. 2002). Therefore, an enhanced stationary wave meridional wind $v^{*}$ is required for balance with reduced equator-to-pole temperature gradient under the background of $\mathrm{AA}$, which leads to an increase in the amplitude of stationary wave (Wills et al. 2019). However, our results show an increase in zoanl wavenumber 1 but a decrease in zonal wavenumber 2 in high latitudes, due to to the increased geopotential height over Novaya Zemlya and Greenland. Our results suggest little evidence for an overall increase in stationary wave amplitude as the Arctic warms.

In terms of Eq. (5), the stationary heat transport is further decomposed into components with zonal wavenumbers $k=1 \sim 3$, which are shown in Fig. 11. The poleward heat transport by zonal wavenumber 1 exhibits an overall increase in the high latitudes, which peaks in the lower troposphere north of $70^{\circ} \mathrm{N}$ (left panels of Fig. 11). The poleward heat transport by wavenumber 2 decreases north of $75^{\circ} \mathrm{N}$ throughout the troposphere and slightly increases south of $75^{\circ} \mathrm{N}$ (middle panels of Fig. 11). The coarse resolution reanalysis, NCEP2, shows large differences from other reanalyses, with decrease in the upper troposphere of midlatitude (Fig. 11f). The poleward heat transport by wavenumber 3 increases north of $75^{\circ} \mathrm{N}$ and decreases south of that latitude with 
small amplitude.

In terms of Eq. (6), results from the decomposition of the stationary poleward moisture transport are similar to that of heat transport (Fig. 12). The poleward moisture transport by zonal wavenumber 1 shows a widespread increase in the high latitudes, with the largest increase in the lower troposphere, which is associated with the enhanced amplitude of zonal wavenumber 1 (left panels of Fig. 12). Meanwhile, corresponding to the reduced amplitude of zonal wavenumber 2, the moisture transport by wavenumber 2 decreases in high latitudes, which is opposite to the changes in moisture transport by zoanl wavenumber 3 . Thus, the key process responsible for the increase of poleward heat and moisture transports by stationary waves is the amplified stationary wave component of zonal wavenumber 1 .

\section{b. Mechanisms for transient heat and moisture transport changes}

Under the influence of AA, meridional temperature gradient is expected to decrease and tend to weaken baroclinicity (Wang et al. 2017). To verify this hypothesis, the vertical structures of the changes in Eady growth rate which is calculated in terms of Eq. (7), meridional potential temperature gradient and Brunt-Väisälä frequency from five reanalyses are displayed in left, central and right panels of Fig. 13, respectively. All the reanalyses demonstrate the decreased baroclinicity in the mid and high latitudes as the Arctic is warming, except for the low-level Arctic (left panels of Fig. 13). A significant decrease in baroclinicity is found along $50^{\circ}-65^{\circ} \mathrm{N}$ from the surface to $400 \mathrm{hPa}$. Another decrease in baroclinicity located in the lower- and midtroposphere over polar region (around $80^{\circ} \mathrm{N}$ ) is evident in ERA-Interim, MERRA-2, 
and CFSR. The changes in baroclinicity follow those in meridional temperature gradient that are characterized by significant decrease in mid and high latitudes, except

371 for the low-level Arctic (central panels of Fig. 13). The reduced static stability

372 contributes to the enhancement of atmospheric baroclinicity over the polar region (right panels of Fig. 13).

To assess the changes of transient eddy activities associated with the reduced atmospheric baroclinicity, we calculate the decadal changes of eddy kinetic energy contributions from low- and high-frequency components, a 121-point lanczos filter is (EKE), which is defined as $E K E=\overline{\left(u^{\prime 2}+v^{\prime 2}\right)} / 2$. To distinguish the relative applied to decompose the transient eddy into its high- (2 10 days) and low-frequency (10 90 days) components. The high-frequency eddies are also known as synoptic eddies, which represent weather patterns such as midlatitude storms. The low-frequency eddies are associated with more persistent weather patterns like blocking. Then the corresponding high- and low-frequency components of EKE are obtained as $E K E_{h}=$ $\overline{\left(u_{h}^{\prime 2}+v_{h}^{\prime 2}\right)} / 2$ and $E K E_{l}=\overline{\left(u_{l}^{\prime 2}+v_{l}^{\prime 2}\right)} / 2$, respectively, where the overbar indicates climatology, and subscripts $h$ and $l$ represent high-frequency and low-frequency components, respectively. The results of decomposition of EKE are shown in Fig. 14. On the whole, the transient EKE decreases above $900 \mathrm{hPa}$ and increases below. MERRA-2 shows the largest decrease among five reanalyses with the center of maximum located in the upper troposphere (left panels of Fig. 14). The EKE changes in NCEP-2 and ERA-Interim are smaller than those in other three reanalyses and statistically insignificant. By comparing the relative contributions from high- and low- 
frequency components, it is found that the high-frequency synoptic EKE changes (middle panels of Fig. 14) are comparable to the total transient EKE changes. The lowfrequency EKE increases between $50^{\circ}$ and $70^{\circ} \mathrm{N}$ and north of $85^{\circ} \mathrm{N}$ and decreases between $70^{\circ} \mathrm{N}$ and $85^{\circ} \mathrm{N}$ with statistical insignificance (right panels of Fig. 14). Hence, the total transient EKE changes are dominated by the synoptic EKE changes, although the latter are partially canceled by the low-frequency EKE changes. These results support the hypothesis that the decreased baroclinicity caused by the weakened meridional temperature gradient is an important contributor to the attenuation of transient eddy activity.

To estimate the role of different wave components in the changes of poleward transport, we apply the same decomposition method as in EKE for poleward heat and moisture transports in all five reanalyses, as shown in Figs. 15 and 16. The left panels of Fig. 15 show the transient poleward heat transport, and the second and third columns are the heat transports by high- and low-frequency eddies, respectively. The changes in transport by transient eddies are not exactly equal to the sum of those by high- and lowfrequency. Because the transient eddies defined here include the eddies with time scale longer than 90 days, which are known as very-low frequency. The changes in poleward transport by very-low frequency are small and can be ignored. It is illustrated that the poleward heat transport by transient eddies decreases over most of the mid and high latitudes except for the upper-level over polar region, which is a common feature of all reanalyses (left panels of Fig. 15). The decreased transient poleward heat transport peaks in the lower troposphere north of $60^{\circ} \mathrm{N}$. The heat transports by both high- and 
low-frequency eddies decrease in the lower troposphere (below $600 \mathrm{hPa}$ ), each contributing half to the transient transport decrease. In the middle- and uppertroposphere, the opposite changes are found for the transport by synoptic and lowfrequency eddies, with the combined changes that decrease south of $70^{\circ} \mathrm{N}$ and slightly increase north of $70^{\circ} \mathrm{N}$.

Similar to Fig. 15, the changes in poleward moisture transport by transient eddies and its components with different time scales are shown in Fig. 16. The poleward transient moisture transport decreases in the lower troposphere except for polar region and increases in the middle- and upper-troposphere (left panels of Fig. 16). The gross features are similar to the synoptic moisture transport, which is characterized by an overall decrease in the middle- and lower-troposphere in the mid and high latitudes and a slight increase in the upper troposphere and near-surface of the Arctic (central panels of Fig. 16). For low-frequency transport, an overall increase is found in the mid and high latitudes with the maximum located at $60^{\circ} \mathrm{N}$ and extending to $500 \mathrm{hPa}$, which is partially offset by the synoptic transport (right panels of Fig. 16). Note that the lowfrequency transport also slightly contributes to the decreased transient transport at low levels of $75^{\circ} \mathrm{N}$. Thus, corresponding to the weakened synoptic eddy activities, the poleward heat and moisture transports by synoptic eddies decrease throughout the troposphere in the high latitudes, which play dominant roles in the total transient transport.

\section{Conclusions and discussion}

This study investigates the influence of the Arctic amplification on the midlatitude 
atmospheric waves and their contributions to the poleward heat and moisture transports. Five atmospheric reanalyses (NCEP2, ERA-Interim, JRA-55, MERRA-2 and CFSR) are used to study wintertime poleward heat and moisture transport changes in the mid and high latitudes associated with the Arctic amplification which is the strongest during the boreal winter for recent two decades. Major conclusions are illustrated in a schematic diagram, as shown in Fig. 17.

In association with the Arctic amplification, the zonal mean wintertime poleward heat and moisture transports by stationary waves increase in the high latitudes, which tend to induce increases in the temperature and moisture over the Arctic, thus acting as a positive feedback onto the Arctic warming. The increases in stationary poleward heat (moisture) transport are primarily due to the increase in stationary wave meridional wind, while the increase in stationary temperature (moisture) contributes little (not shown). The enhanced stationary transports are mainly contributed from the increased transport by stationary wave component with zonal wavenumber 1 . Our result shows an increase in the amplitude of stationary wave component with zonal wavenumber 1 but a decrease in that with zonal wavenumber 2 . This result is different from what is expected by the dry dynamical mechanism based on the reduced equator-to-pole temperature gradient (Hoskins and Karoly 1981; Wills et al. 2019) and is a step forward from previous studies that suggested increased stationary wave amplitude (Francis and Vavrus 2012; Liu et al. 2012).

On the other hand, the amplified Arctic warming decreases the transient eddy activities by reducing the low-level equator-to-pole temperature gradient and 
baroclinicity in the high latitudes, which results in the decreases of both poleward heat and moisture transports by transient eddies. The weakened eddy heat flux in the $\mathrm{NH}$ associated with a decrease in meridional temperature gradient that arises from AA has also been well captured by observational studies and climate models (Chemke and Polvani 2020). The reductions in the poleward transport by transient eddies tend to check the Arctic warming and moistening, thus generating a negative feedback. In total, the increased poleward heat transport by stationary waves is nearly cancelled by the decreased poleward heat transport by transient eddies. Thus, the total poleward heat transport shows minor changes, contributing little to the Arctic warming. However, the total poleward moisture transport increases over most areas of the high latitudes where the role of stationary waves is dominant. These changes by epoch differences are significantly consistent with the interanuual anomalies in transport and flux convergence as regressed upon the Arctic warming index. Therefore, the poleward moisture transport increase by stationary waves which acts as a positive feedback plays a crucial role in the Arctic amplification during winter when the ice-albedo feedback vanishes.

The results are compared well among four high-resolution reanalyses, while NCEP2 is often in disagreement with other four reanalyses. The relatively coarse model resolution $(\mathrm{T} 62, \sim 210 \mathrm{~km})$ used in NCEP2 which may underestimate transient eddy activities is likely the reason for the differences (Hodges et al. 2011). Moreover, retrieves of satellite data employed may also cause difference (as shown in Table 1), especially over the polar region. It implies that it is better to use the high-resolution 
reanalyses (ERA-Interim, JRA-55, MERRA-2 and CFSR) in the study of eddy-related issues in the mid and high latitudes.

In this study, we examine the impact of the Arctic amplification on the mid and high latitude stationary waves and transient eddies and their relative contributions and potential feedbacks onto the amplified Arctic warming, in a manner of two-way interactions on decadal timescale. We find the importance and positive feedback role of poleward moisture transport in amplifying the Arctic warming. This finding agrees with those presented by other recent studies showing an increase of poleward moisture flux and its positive effect on the Arctic SAT (Graversen and Burtu 2016; Woods and Caballero 2016; Lee et al. 2017a). However, for moisture transport, we only consider the contribution of moisture transport to the Arctic moistening through moisture budget analysis. To examine the feedback more comprehensively, the longwave radiation effect of the Arctic moistening needs to be further identified in the future study, which is suggested to be an important contributor to the Arctic warming and sea ice decline especially during winter when the ice-albedo feedback vanishes (Park et al. 2015a; Lee et al. 2017b).

Although our current study provides a new insight into the amplified Arctic warming and midlatitude linkage, the results are limited to a relatively short period (1980-2016) which may affect the statistical confidence, given the large internal variabilities in the mid and high latitudes. A major caveat of observational studies is that correlation alone cannot provide any unambiguous support for causality. Cause and effect can be established through sensitivity or perturbation studies using dedicated 
model simulations, but models are subject to several deficiencies. Model experiments

502 forced with the Arctic sea-ice loss produce significantly different circulation responses

503 (Peings and Magnusdottir 2014; Screen et al. 2014), which are mainly caused by the

504 sensitivity to the magnitude (Chen et al. 2016) and geographic patterns of sea-ice loss

505 (Pedersen et al. 2016; Screen 2017) and the highly nonlinear interactions among model

506 processes. Meanwhile, it is inaccurate to characterize the Arctic amplification only with

507 sea ice loss, because other processes, such as poleward transport from outside the Arctic,

508 are also critical to the Arctic warming (Screen et al. 2012; Ding et al. 2014; Park et al.

509 2015b; Gong et al. 2017). To make further progress, adequate description of the

510 underlying physical processes behind the Arctic warming and coordinated experiments

511 with as many different models as possible are needed (Screen et al. 2018). 
This study is supported by the National Natural Science Foundation of China

514 (Grant Nos. 41621005 and 41875086) and the National Key Basic Research and

515 Development Program of China (Grant No. 2018YFC1505902). We are also grateful

516 for support from the Jiangsu Collaborative Innovation Center for Climate Change.

517 NCEP2 was provided by the NOAA/OAR/ESRL PSD, Boulder, Colorado, USA, and

518 was obtained from the website at https://www.esrl.noaa.gov/psd/. The ERA-Interim

519 data was produced by ECMWF and was obtained from https://apps.ecmwf.int/datasets/.

520 The JRA-55 data was developed by the Japan Meteorological Agency (JMA) and is

521 available at https://jra.kishou.go.jp/JRA-55/index_en.html. MERRA-2 is available at

522 https://gmao.gsfc.nasa.gov/reanalysis/MERRA-2/data_access/. The CFSR data was

523 provided by Research Data Archive at the National Center for Atmospheric Research

524 and is available at http://dx.doi.org/10.5065/D69K487J. 


\section{References}

Alexeev VA, Langen PL, Bates JR (2005) Polar amplification of surface warming on an aquaplanet in "ghost forcing" experiments without sea ice feedbacks Climate Dynamics 24:655-666. https://doi.org/10.1007/s00382-005-0018-3

Barnes EA (2013) Revisiting the evidence linking Arctic amplification to extreme weather in midlatitudes Geophysical Research Letters 40:4734-4739. https://doi.org/10.1002/grl.50880

Barnes EA, Screen JA (2015) The impact of Arctic warming on the midlatitude jetstream: Can it? Has it? Will it? Wiley Interdiplinary Reviews: Climate Change 6:277-286. https://doi.org/10.1002/wcc.337

Blender R, Schubert M (2000) Cyclone Tracking in Different Spatial and Temporal Resolutions Monthly Weather Review 128:377-384. https://doi.org/10.1175/1520-0493(2000)128<0377:CTIDSA $>2.0 . C O ; 2$

Boer GJ, Shepherd TG (1983) Large-Scale Two-Dimensional Turbulence in the Atmosphere Journal of Atmospheric Sciences 40:164-184. https://doi.org/10.1175/1520-0469(1983)040<0164:LSTDTI >2.0.CO;2

Bromwich DH, Fogt RL, Hodges KI, Walsh JE (2007) A tropospheric assessment of the ERA-40, NCEP, and JRA-25 global reanalyses in the polar regions Journal of Geophysical Research:

Atmospheres

112. https://doi.org/10.1029/2006JD007859

Chemke R, Polvani LM (2020) Linking midlatitudes eddy heat flux trends and polar amplification npj Climate and Atmospheric Science 3:8. https://doi.org/10.1038/s41612-020-0111-7

Chen HW, Zhang F, Alley RB (2016) The Robustness of Midlatitude Weather Pattern Changes due to Arctic Sea Ice Loss Journal of Climate 29:7831-7849. https://doi.org/10.1175/jcli-d-16-0167.1

Cohen J et al. (2014) Recent Arctic amplification and extreme mid-latitude weather Nature Geoscience 7:627-637. https://doi.org/10.1038/ngeo2234

Cohen J et al. (2020) Divergent consensuses on Arctic amplification influence on 
midlatitude severe winter weather Nature Climate Change 10:20-29. https://doi.org/10.1038/s41558-019-0662-y

Coumou D, Lehmann J, Beckmann J (2015) The weakening summer circulation in the

Graversen RG, Burtu M (2016) Arctic amplification enhanced by latent energy 

transport of atmospheric planetary waves Quarterly Journal of the Royal Meteorological Society 142:2046-2054. https://doi.org/10.1002/qj.2802

Graversen RG, Mauritsen T, Tjernström M, Källén E, Svensson G (2008) Vertical structure of recent Arctic warming Nature 451:53-56. https://doi.org/10.1038/nature06502

Graversen RG, Wang M (2009) Polar amplification in a coupled climate model with locked albedo Climate Dynamics 33:629-643. https://doi.org/10.1007/s00382$\underline{009-0535-6}$

Harada Y et al. (2016) The JRA-55 Reanalysis: Representation of Atmospheric Circulation and Climate Variability Journal of the Meteorological Society of Japan Ser II 94:269-302. https://doi.org/10.2151/jmsj.2016-015

Held IM, Ting M, Wang H (2002) Northern Winter Stationary Waves: Theory and Modeling Journal of Climate 15:2125-2144. https://doi.org/10.1175/1520$\underline{0442(2002) 015<2125: \text { Nwswta }>2.0 . C o ; 2}$

Hodges KI, Lee RW, Bengtsson L (2011) A Comparison of Extratropical Cyclones in Recent Reanalyses ERA-Interim, NASA MERRA, NCEP CFSR, and JRA-25 Journal of Climate 24:4888-4906. https://doi.org/10.1175/2011jcli4097.1

Hoskins BJ, Karoly DJ (1981) The Steady Linear Response of a Spherical Atmosphere to Thermal and Orographic Forcing Journal of Atmospheric Sciences 38:11791196. https://doi.org/10.1175/1520-0469(1981)038<1179:Tslroa $>2.0 . C o ; 2$

Hoskins BJ, Valdes PJ (1990) On the Existence of Storm-Tracks Journal of the Atmospheric Sciences 47:1854-1864. https://doi.org/10.1175/15200469(1990)047<1854:OTEOST>2.0.CO;2

Jung T et al. (2012) High-Resolution Global Climate Simulations with the ECMWF Model in Project Athena: Experimental Design, Model Climate, and Seasonal Forecast Skill Journal of Climate 25:3155-3172. https://doi.org/10.1175/jcli-d$\underline{11-00265.1}$

Kanamitsu M, Ebisuzaki W, Woollen J, Yang S-K, Hnilo JJ, Fiorino M, Potter GL (2002) NCEP-DOE AMIP-II Reanalysis (R-2) Bulletin of the American 

$\underline{1631}$

Lee HJ et al. (2017a) Impact of Poleward Moisture Transport from the North Pacific on the Acceleration of Sea Ice Loss in the Arctic since 2002 Journal of Climate 30:6757-6769. https://doi.org/10.1175/jcli-d-16-0461.1

Lee S, Gong T, Feldstein SB, Screen JA, Simmonds I (2017b) Revisiting the Cause of the 1989-2009 Arctic Surface Warming Using the Surface Energy Budget: Downward Infrared Radiation Dominates the Surface Fluxes Geophysical Research Letters 44:10,654-610,661. https://doi.org/10.1002/2017GL075375

Lee S, Gong T, Johnson N, Feldstein SB, Pollard D (2011) On the Possible Link between Tropical Convection and the Northern Hemisphere Arctic Surface Air Temperature Change between 1958 and 2001 Journal of Climate 24:4350-4367. https://doi.org/10.1175/2011jcli4003.1

Lindsay R, Wensnahan M, Schweiger A, Zhang J (2014) Evaluation of Seven Different Atmospheric Reanalysis Products in the Arctic Journal of Climate 27:25882606. https://doi.org/10.1175/jcli-d-13-00014.1

Lindzen RS, Farrell B (1980) A Simple Approximate Result for the Maximum Growth Rate of Baroclinic Instabilities Journal of Atmospheric Sciences 37:1648-1654. https://doi.org/10.1175/1520-0469(1980)037<1648:Asarft>2.0.Co;2

Liu C, Barnes EA (2015) Extreme moisture transport into the Arctic linked to Rossby wave breaking Journal of Geophysical Research: Atmospheres 120:3774-3788. https://doi.org/10.1002/2014JD022796

Liu J, Curry JA, Wang H, Song M, Horton RM (2012) Impact of declining Arctic sea ice on winter snowfall Proceedings of the National Academy of Sciences 109:4074-4079. https://doi.org/10.1073/pnas.1114910109

Overland J, Francis JA, Hall R, Hanna E, Kim S-J, Vihma T (2015) The Melting Arctic and Midlatitude Weather Patterns: Are They Connected?* Journal of Climate 28:7917-7932. https://doi.org/10.1175/JCLI-D-14-00822.1

Overland JE (2016) A difficult Arctic science issue: Midlatitude weather linkages Polar 
Science 10:210-216. https://doi.org/10.1016/j.polar.2016.04.011

Park D-SR, Lee S, Feldstein SB (2015a) Attribution of the Recent Winter Sea Ice Decline over the Atlantic Sector of the Arctic Ocean Journal of Climate 28:4027-4033. https://doi.org/10.1175/jcli-d-15-0042.1

Park HS, Lee S, Son S-W, Feldstein SB, Kosaka Y (2015b) The Impact of Poleward Moisture and Sensible Heat Flux on Arctic Winter Sea Ice Variability Journal of Climate 28:5030-5040. https://doi.org/10.1175/jcli-d-15-0074.1

Pedersen RA, Cvijanovic I, Langen PL, Vinther BM (2016) The Impact of Regional Arctic Sea Ice Loss on Atmospheric Circulation and the NAO Journal of Climate 29:889-902. https://doi.org/10.1175/jcli-d-15-0315.1

Peings Y, Magnusdottir G (2014) Response of the Wintertime Northern Hemisphere Atmospheric Circulation to Current and Projected Arctic Sea Ice Decline: A Numerical Study with CAM5 Journal of Climate 27:244-264. https://doi.org/10.1175/jcli-d-13-00272.1

Peixoto JP, Oort AH (1992) Physics of Climate. American Institute of Physics, New York,

Petoukhov V, Rahmstorf S, Petri S, Schellnhuber HJ (2013) Quasiresonant amplification of planetary waves and recent Northern Hemisphere weather extremes Proceedings of the National Academy of Sciences 110:5336-5341. https://doi.org/10.1073/pnas.1222000110

Saha S et al. (2010) The NCEP Climate Forecast System Reanalysis Bulletin of the American Meteorological Society 91:1015-1058. https://doi.org/10.1175/2010bams3001.1

Screen JA (2017) Simulated Atmospheric Response to Regional and Pan-Arctic Sea Ice Loss Journal of Climate 30:3945-3962. https://doi.org/10.1175/jcli-d-16-0197.1

Screen JA, Deser C, Simmonds I (2012) Local and remote controls on observed Arctic $\begin{array}{llll}\text { warming } & \text { Geophysical } & \text { Research }\end{array}$ https://doi.org/10.1029/2012GL051598

Screen JA, Deser C, Simmonds I, Tomas R (2014) Atmospheric impacts of Arctic sea- 
ice loss, 1979-2009: separating forced change from atmospheric internal variability Climate Dynamics 43:333-344. https://doi.org/10.1007/s00382-0131830-9

Screen JA et al. (2018) Consistency and discrepancy in the atmospheric response to Arctic sea-ice loss across climate models Nature Geoscience 11:155-163. https://doi.org/10.1038/s41561-018-0059-y

Screen JA, Simmonds I (2010a) The central role of diminishing sea ice in recent Arctic temperature amplification Nature 464:1334-1337. https://doi.org/10.1038/nature09051

Screen JA, Simmonds I (2010b) Increasing fall-winter energy loss from the Arctic Ocean and its role in Arctic temperature amplification Geophysical Research Letters 37. https://doi.org/10.1029/2010GL044136

Screen JA, Simmonds I (2013) Exploring links between Arctic amplification and midlatitude weather Geophysical Research Letters 40:959-964. https://doi.org/10.1002/grl.50174

Screen JA, Simmonds I (2014) Amplified mid-latitude planetary waves favour particular regional weather extremes Nature Climate Change 4:704-709. https://doi.org/10.1038/nclimate2271

Serreze MC, Barrett AP, Stroeve JC, Kindig DN, Holland MM (2009) The emergence of surface-based Arctic amplification The Cryosphere Discussions 2:601. https://doi.org/10.5194/tc-3-11-2009

Serreze MC, Francis JA (2006) The Arctic Amplification Debate Climatic Change 76:241-264. https://doi.org/10.1007/s10584-005-9017-y

Tilinina N, Gulev SK, Rudeva I, Koltermann P (2013) Comparing Cyclone Life Cycle Characteristics and Their Interannual Variability in Different Reanalyses Journal of Climate 26:6419-6438. https://doi.org/10.1175/jcli-d-12-00777.1

Vavrus SJ (2018) The Influence of Arctic Amplification on Mid-latitude Weather and Climate Current Climate Change Reports 4:238-249. https://doi.org/10.1007/s40641-018-0105-2 
Walsh JE (2014) Intensified warming of the Arctic: Causes and impacts on middle latitudes Global and Planetary Change 117:52-63. https://doi.org/10.1016/j.gloplacha.2014.03.003

Wang J, Kim H-M, Chang EKM (2017) Changes in Northern Hemisphere Winter Storm Tracks under the Background of Arctic Amplification Journal of Climate 30:3705-3724. https://doi.org/10.1175/jcli-d-16-0650.1

Wills RCJ, White RH, Levine XJ (2019) Northern Hemisphere Stationary Waves in a Changing Climate Current Climate Change Reports 5:372-389. https://doi.org/10.1007/s40641-019-00147-6

Woods C, Caballero R (2016) The Role of Moist Intrusions in Winter Arctic Warming and Sea Ice Decline Journal of Climate 29:4473-4485. https://doi.org/10.1175/jcli-d-15-0773.1

Zhang X, He J, Zhang J, Polyakov I, Gerdes R, Inoue J, Wu P (2013) Enhanced poleward moisture transport and amplified northern high-latitude wetting trend Nature Climate Change 3:47-51. https://doi.org/10.1038/nclimate1631 
716 Table 1. Detailed information of the five atmospheric reanalyses used in the study.

\begin{tabular}{|c|c|c|c|c|c|c|c|}
\hline Reanalysis name & Organization & Date range & Horizontal resolution & Vertical layer & Products resolution & $\begin{array}{l}\text { Assimilation } \\
\text { Algorithm }\end{array}$ & Satellite data \\
\hline NCEP-DOE2 & NCEP/DOE & $1979-2017$ & $\mathrm{~T} 62(\sim 210 \mathrm{~km})$ & 28 levels & $2.5^{\circ} \times 2.5^{\circ}$ & 3DVAR & Retrievals \\
\hline ERA-Interim & ECMWF & $1979-2017$ & $\mathrm{~T} 255(\sim 79 \mathrm{~km})$ & 60 levels & $1.5^{\circ} \times 1.5^{\circ}$ & 4DVAR & Radiances \\
\hline JRA-55 & JMA & $1958-2017$ & $\mathrm{~T} 319(\sim 60 \mathrm{~km})$ & 40 levels & $1.25^{\circ} \times 1.25^{\circ}$ & 4DVAR & Radiances \\
\hline MERRA-2 & NASA GMAO & $1980-2017$ & $(2 / 3)^{\circ} \times 0.5^{\circ}(\sim 50 \mathrm{~km})$ & 72 levels & $0.5^{\circ} \times 0.66^{\circ}$ & 3DVAR & Radiances \\
\hline CFSR & NCEP & $1979-2017$ & $\mathrm{~T} 382(\sim 38 \mathrm{~km})$ & 64 levels & $0.5^{\circ} \times 0.5^{\circ}$ & 3DVAR & Radiances \\
\hline
\end{tabular}

717 
719 Figure 1. Surface air temperature anomalies (K) averaged over the globe for (a) DJF, 720 (b) MAM, (c) JJA, and (d) SON. (e)-(h) and (i)-(l) are as in (a)-(d), but for those averaged over $0^{\circ} \sim 60^{\circ} \mathrm{N}$ and $60^{\circ} \sim 90^{\circ} \mathrm{N}$, respectively. The climatological means are for 1980-2016. The colored solid lines denote the average of five reanalyses and the shaded envelopes show the spread among the five reanalyses.

Figure 2. Wintertime surface air temperature differences (K) between 1999-2016 and 1981-1998 in (a) NCEP2, (b) ERA-Interim, (c) JRA-55, (d) MERRA-2, and (e) CFSR. The differences with values exceeding the $90 \%(\mathrm{p}<0.1)$ significance level according to the Student's $t$-test are crossed.

Figure 3. Wintertime zonally-averaged temperature (K, left panels) and specific humidity $\left(10^{-4} \mathrm{~kg} / \mathrm{kg}\right.$, right panels) differences between 1999-2016 and 1981-1998 in (a, b) NCEP2, (c, d) ERA-Interim, (e, f) JRA-55, (g, h) MERRA-2, and (i, j) CFSR. The differences with values exceeding the $90 \%(\mathrm{p}<0.1)$ significance level according to the Student's $t$-test are crossed.

Figure 4. Decadal differences between 1999-2016 and 1981-1998 of wintertime zonally-averaged poleward heat transport $(\mathrm{K} \mathrm{m} / \mathrm{s})$ by total disturbances (left panels), stationary waves (central panels), and transient eddies (right panels) with five atmospheric reanalyses (NCEP2, ERA-I, JRA-55, MERRA-2, and CFSR; from upper to lower panels). The zero lines are shown in bold black. The differences with values exceeding the $90 \%(\mathrm{p}<0.1)$ significance level according to the Student's $t$-test are crossed.

740 Figure 5. As in Fig. 4 , but for the poleward moisture transport $\left(10^{-4} \mathrm{~kg} / \mathrm{kg} \mathrm{m} / \mathrm{s}\right)$.

741 Figure 6. As in Fig. 4 , but for the convergence (K/day) of poleward heat transport.

742 Figure 7. As in Fig. 4 , but for the convergence $\left(10^{-5} \mathrm{~kg} / \mathrm{kg} /\right.$ day $)$ of poleward moisture 743 transport. 
Figure 8. Wintertime zonally-averaged interannual anomalies of poleward heat $(\mathrm{K} \mathrm{m} / \mathrm{s}$, upper panels) and moisture $\left(10^{-4} \mathrm{~kg} / \mathrm{kg} \mathrm{m} / \mathrm{s}\right.$, lower panels) transports by total disturbances (left panels), stationary waves (central panels), and transient eddies (right panels), regressed upon a normalized Arctic warming index defined as the surface air temperature anomaly averaged over $75^{\circ} \sim 90^{\circ} \mathrm{N}$ and $0^{\circ} \sim 360^{\circ}$. The zero lines are shown in bold black. The anomalies with values exceeding the $90 \%(\mathrm{p}<0.1)$ significance level according to the Student's $t$-test are crossed. Note that the CFSR reanalysis dataset is only used here.

Figure 9. As in Fig. 8, but for the convergences of interannual anomalies of poleward heat (upper panels) and moisture (lower panels) transports.

Figure 10. Decadal differences between 1999-2016 and 1981-1998 of the wintertime $500 \mathrm{hPa}$ geopotential height (gpm, left panels) and the amplitude of stationary waves with zoanl wavenumber 1 6 (gpm, right panels), with five atmospheric reanalyses (NCEP2, ERA-I, JRA-55, MERRA-2, and CFSR; from upper to lower panels). The contours in left panels are $5100 \mathrm{~m}$ and $5180 \mathrm{~m}$ for 1999-2016 (black) and 1981-1998 (green), respectively. The bold black lines in right panels indicate the zero lines.

Figure 11. Decadal differences between 1999-2016 and 1981-1998 of wintertime zonally-averaged poleward heat transport by stationary wave component $(\mathrm{K} \mathrm{m} / \mathrm{s})$ of zonal wavenumber 1 (left panels), wavenumber 2 (central panels), and wavenumber 3 (right panels) with five atmospheric reanalyses (NCEP2, ERA-I, JRA-55, MERRA-2, and CFSR; from upper to lower panels). The zero lines are shown in bold black lines. Figure 12. As in Fig. 11, but for the poleward moisture transport $\left(10^{-4} \mathrm{~kg} / \mathrm{kg} \mathrm{m} / \mathrm{s}\right)$.

Figure 13. Decadal differences between 1999-2016 and 1981-1998 of wintertime zonally-averaged maximum Eady growth rate (1/day) (left panels), meridional potential temperature gradient $\left(10^{-4} \mathrm{~K} / \mathrm{km}\right)$ (central panels), and Brunt-Väis $\ddot{a} 1 \ddot{a}$ frequency $\left(10^{-4} 1 / \mathrm{s}\right)$ (right panels) with five atmospheric reanalyses (NCEP2, ERA-I, JRA-55, MERRA-2, and CFSR; from upper to lower panels). The zero lines are shown in bold black. The differences with values exceeding the $90 \%(\mathrm{p}<0.1)$ significance level according to the Student's $t$-test are crossed.

Figure 14. Decadal differences between 1999-2016 and 1981-1998 of wintertime 
774 zonally-averaged eddy kinetic energy $\left(\mathrm{m}^{2} / \mathrm{s}^{2}\right)$ of total transient eddies (left panels),

775 high-frequency eddies with time-scale of 2-10 days (central panels), and low-frequency

776 eddies with time-scale of 10-90 days (right panels), calculated with five atmospheric

777 reanalyses (NCEP2, ERA-I, JRA-55, MERRA-2, and CFSR; from upper to lower

778 panels). The zero lines are shown in bold black. The differences with values exceeding

779 the $90 \%(\mathrm{p}<0.1)$ significance level according to the Student's $t$-test are crossed.

780 Figure 15. As in Fig. 14, but for the poleward heat transport $(\mathrm{K} \mathrm{m} / \mathrm{s})$.

781 Figure 16. As in Fig. 14, but for the poleward moisture transport $\left(10^{-4} \mathrm{~kg} / \mathrm{kg} \mathrm{m} / \mathrm{s}\right)$.

782 Figure 17. A schematic diagram for the impact of the amplified Arctic warming on the 783 high latitude poleward heat and moisture transports by stationary waves and transient 784 eddies and their possible feedbacks. 

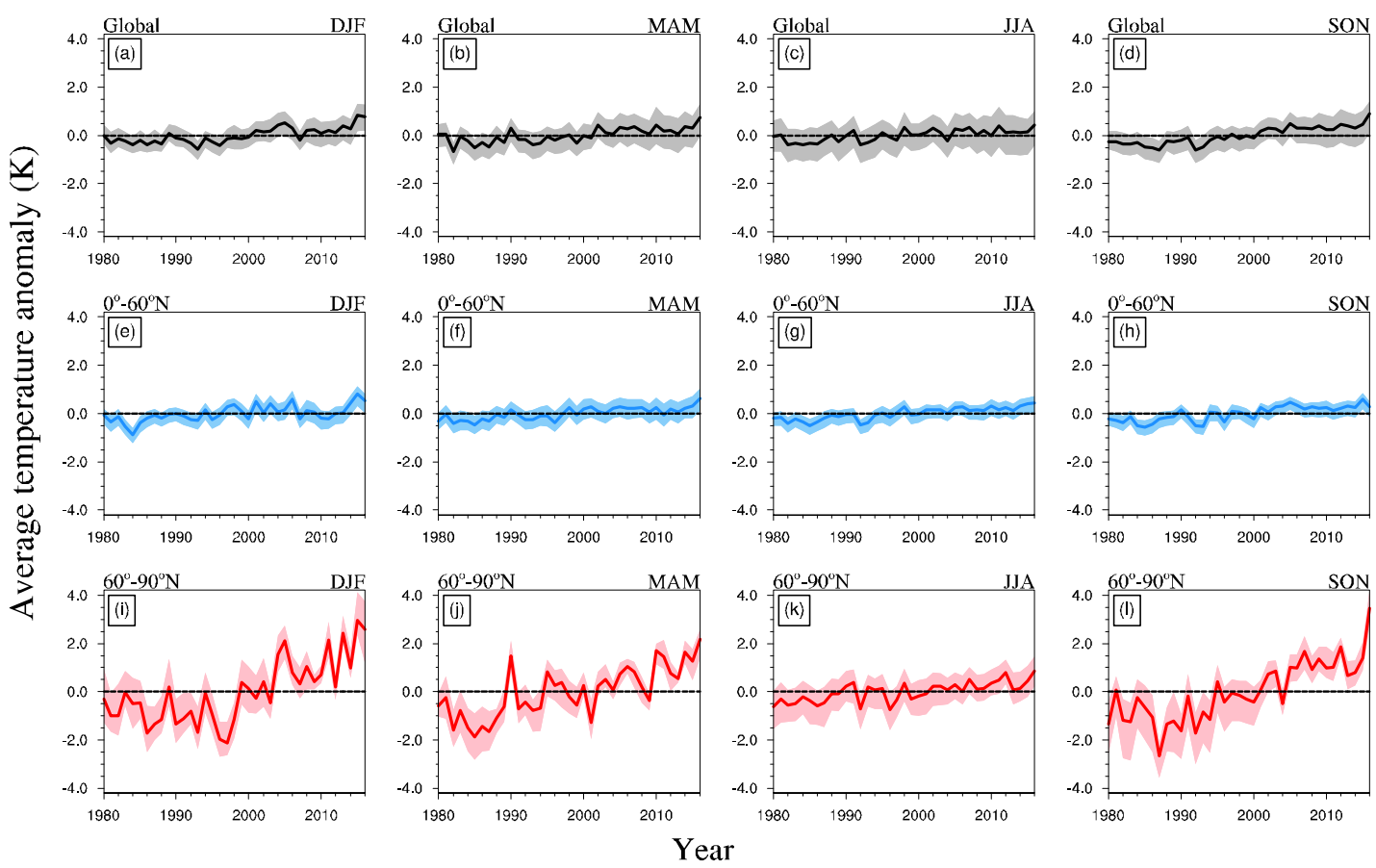

Figure 1. Surface air temperature anomalies (K) averaged over the globe for (a) DJF, (b) MAM, (c) JJA, and (d) SON. (e)-(h) and (i)-(l) are as in (a)-(d), but for those

790 averaged over $0^{\circ} \sim 60^{\circ} \mathrm{N}$ and $60^{\circ} \sim 90^{\circ} \mathrm{N}$, respectively. The climatological means are 791 for 1980-2016. The colored solid lines denote the average of five reanalyses and the 792 shaded envelopes show the spread among the five reanalyses. 


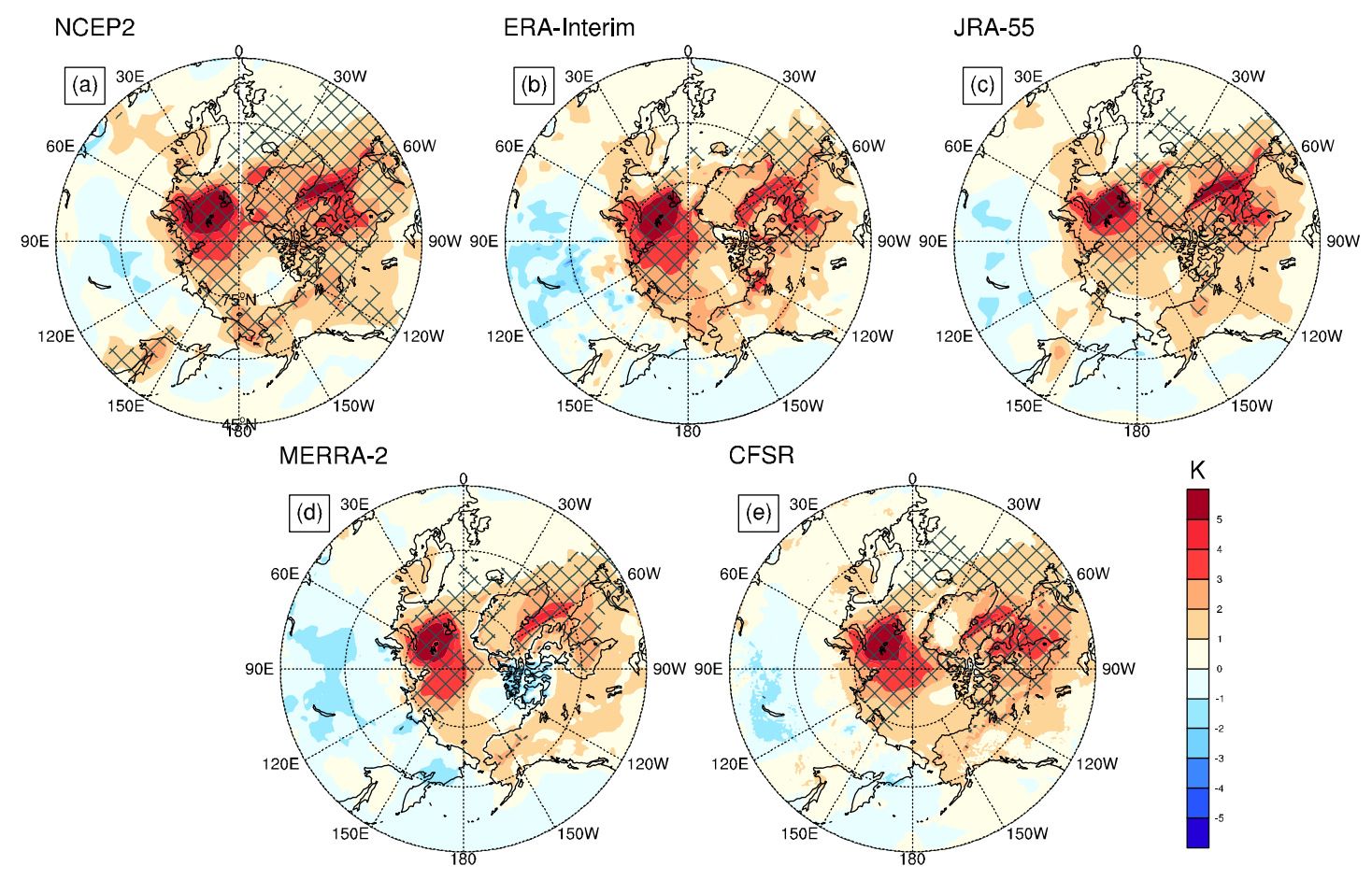

795 Figure 2. Wintertime surface air temperature differences (K) between 1999-2016 and 796 1981-1998 in (a) NCEP2, (b) ERA-Interim, (c) JRA-55, (d) MERRA-2, and (e) CFSR. 797 The differences with values exceeding the $90 \%(\mathrm{p}<0.1)$ significance level according to 798 the Student's $t$-test are crossed. 

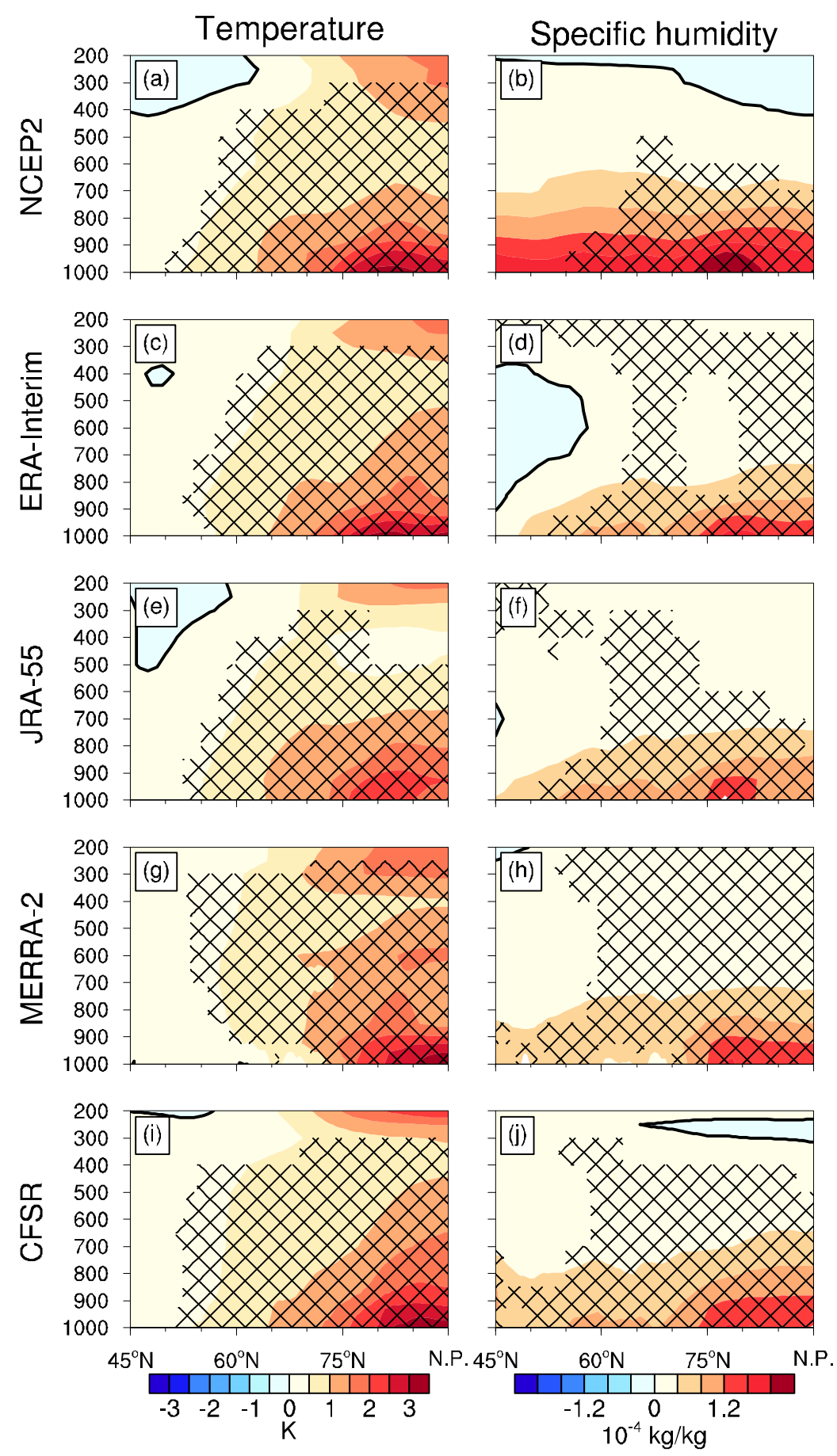

800

801 Figure 3. Wintertime zonally-averaged temperature (K, left panels) and specific 802 humidity $\left(10^{-4} \mathrm{~kg} / \mathrm{kg}\right.$, right panels) differences between 1999-2016 and 1981-1998 in 803 (a, b) NCEP2, (c, d) ERA-Interim, (e, f) JRA-55, (g, h) MERRA-2, and (i, j) CFSR. 804 The differences with values exceeding the $90 \%(\mathrm{p}<0.1)$ significance level according to 805 the Student's $t$-test are crossed. 

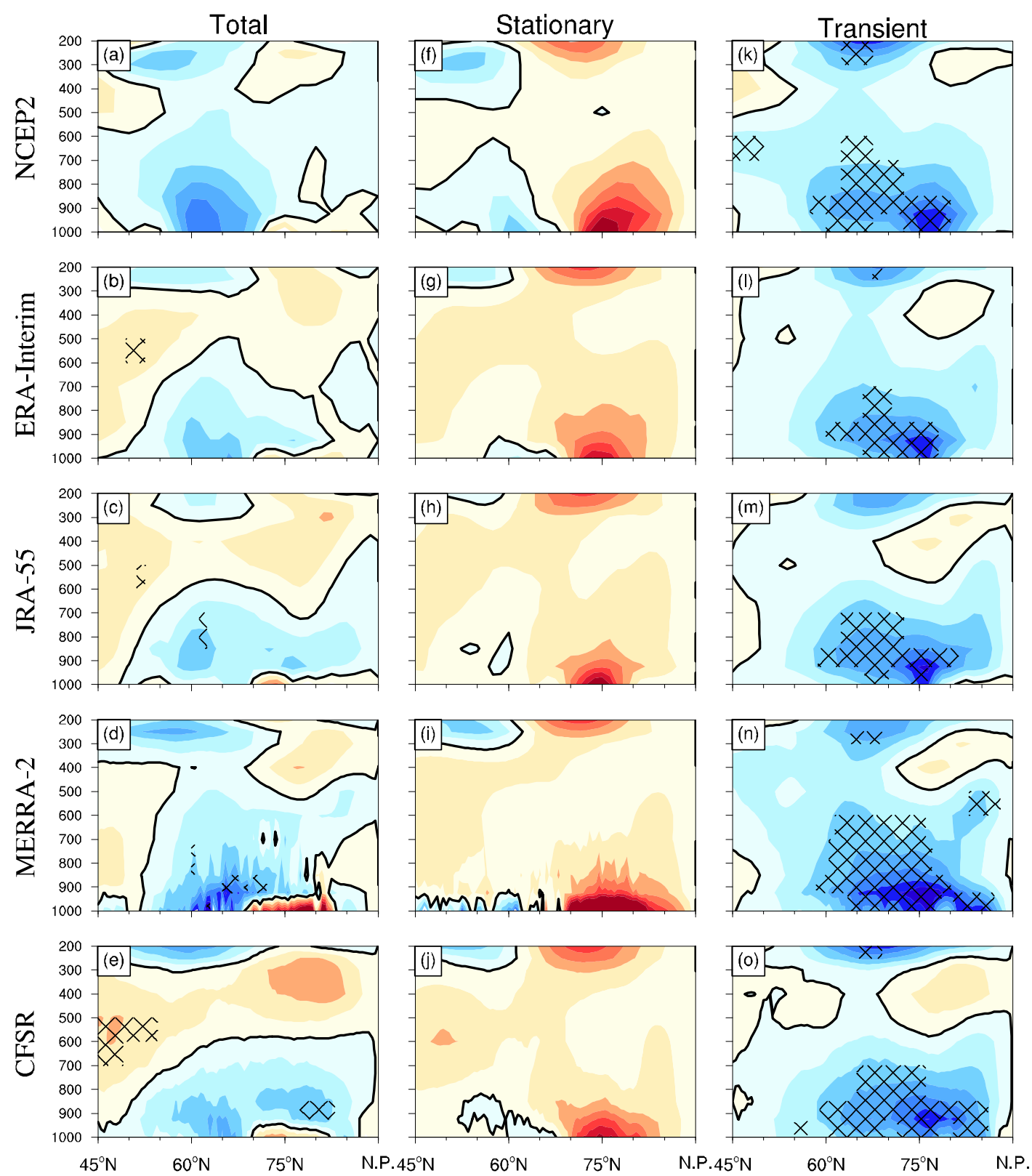

807

808

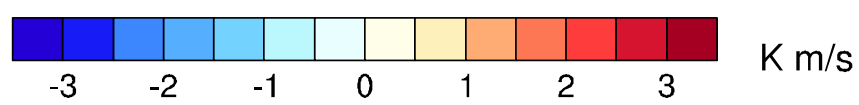

Figure 4. Decadal differences between 1999-2016 and 1981-1998 of wintertime zonally-averaged poleward heat transport $(\mathrm{K} \mathrm{m} / \mathrm{s})$ by total disturbances (left panels), stationary waves (central panels), and transient eddies (right panels) with five atmospheric reanalyses (NCEP2, ERA-I, JRA-55, MERRA-2, and CFSR; from upper to lower panels). The zero lines are shown in bold black. The differences with values exceeding the $90 \%(\mathrm{p}<0.1)$ significance level according to the Student's $t$-test are crossed. 

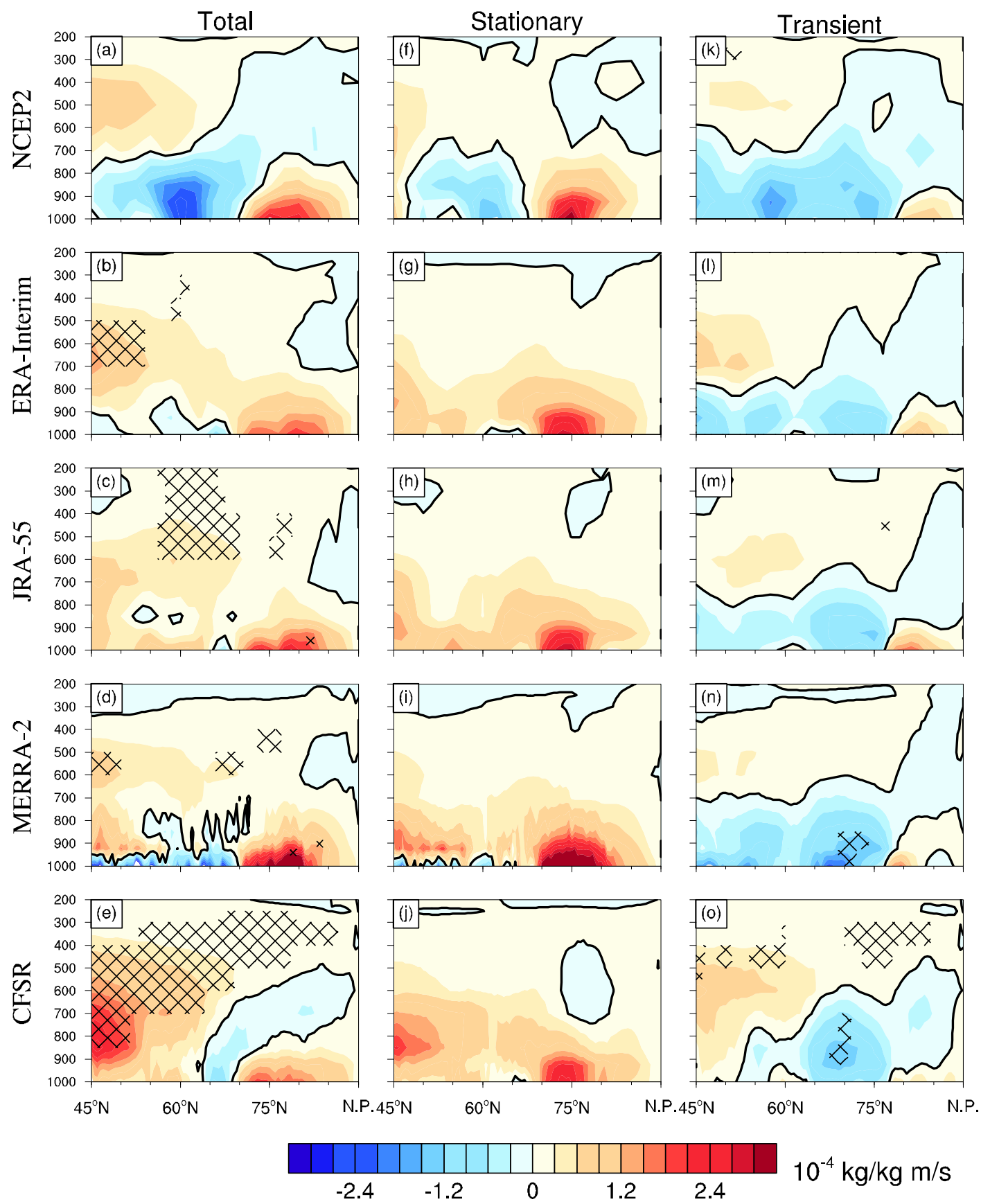

817 Figure 5. As in Fig. 4 , but for the poleward moisture transport $\left(10^{-4} \mathrm{~kg} / \mathrm{kg} \mathrm{m} / \mathrm{s}\right)$. 

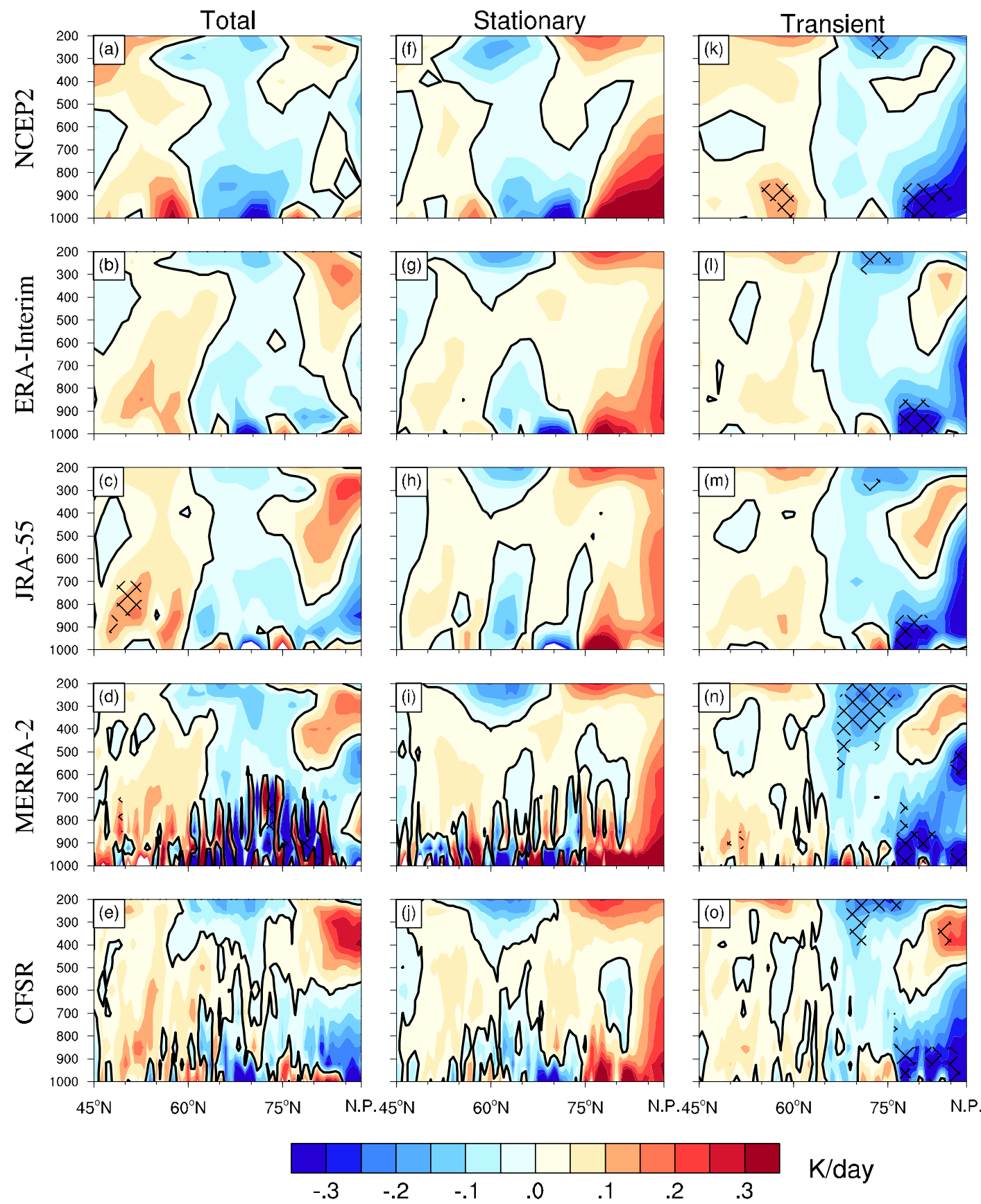

819 Figure 6. As in Fig. 4 , but for the convergence (K/day) of poleward heat transport. 

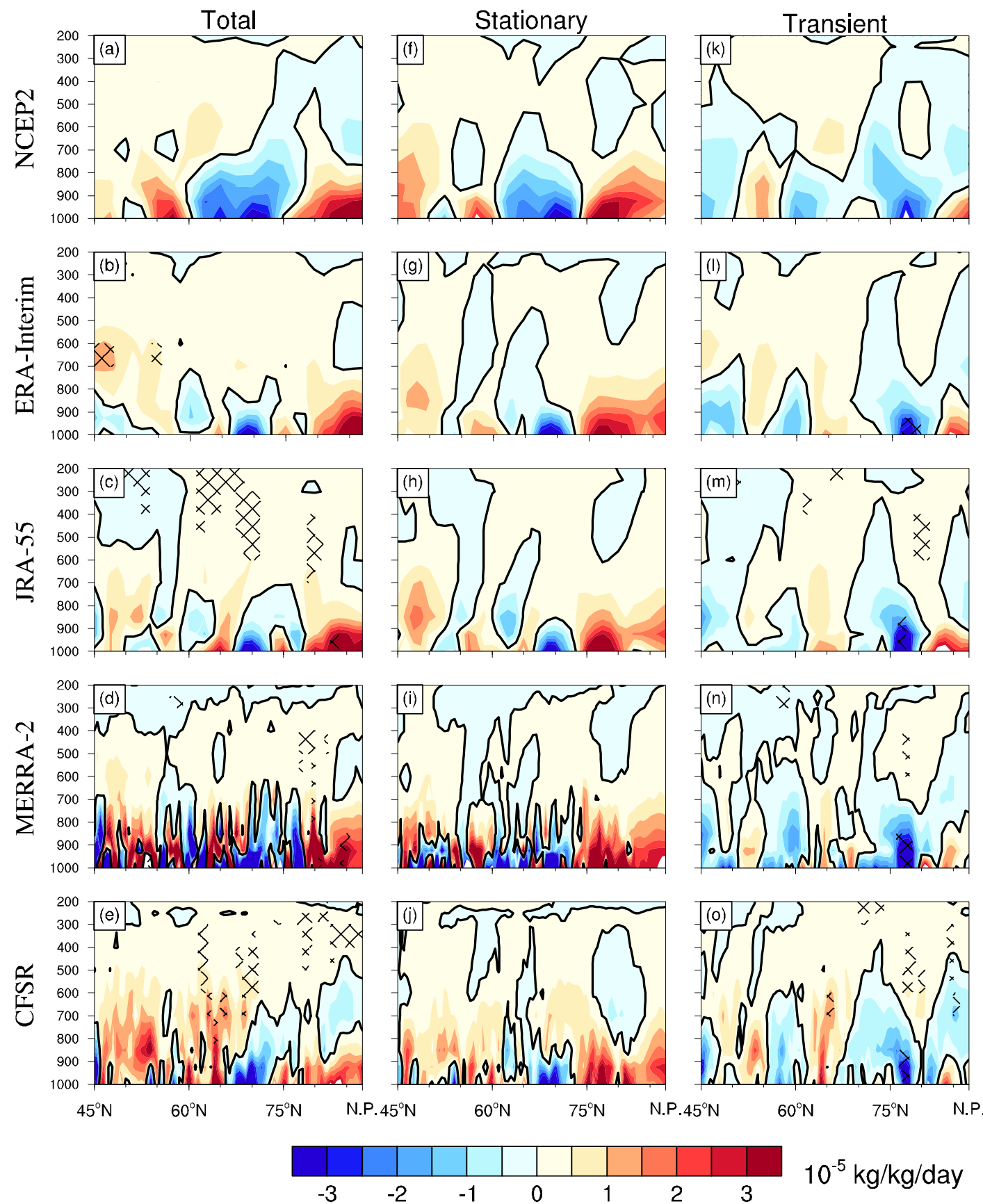

822

Figure 7. As in Fig. 4 , but for the convergence $\left(10^{-5} \mathrm{~kg} / \mathrm{kg} /\right.$ day $)$ of poleward moisture transport. 

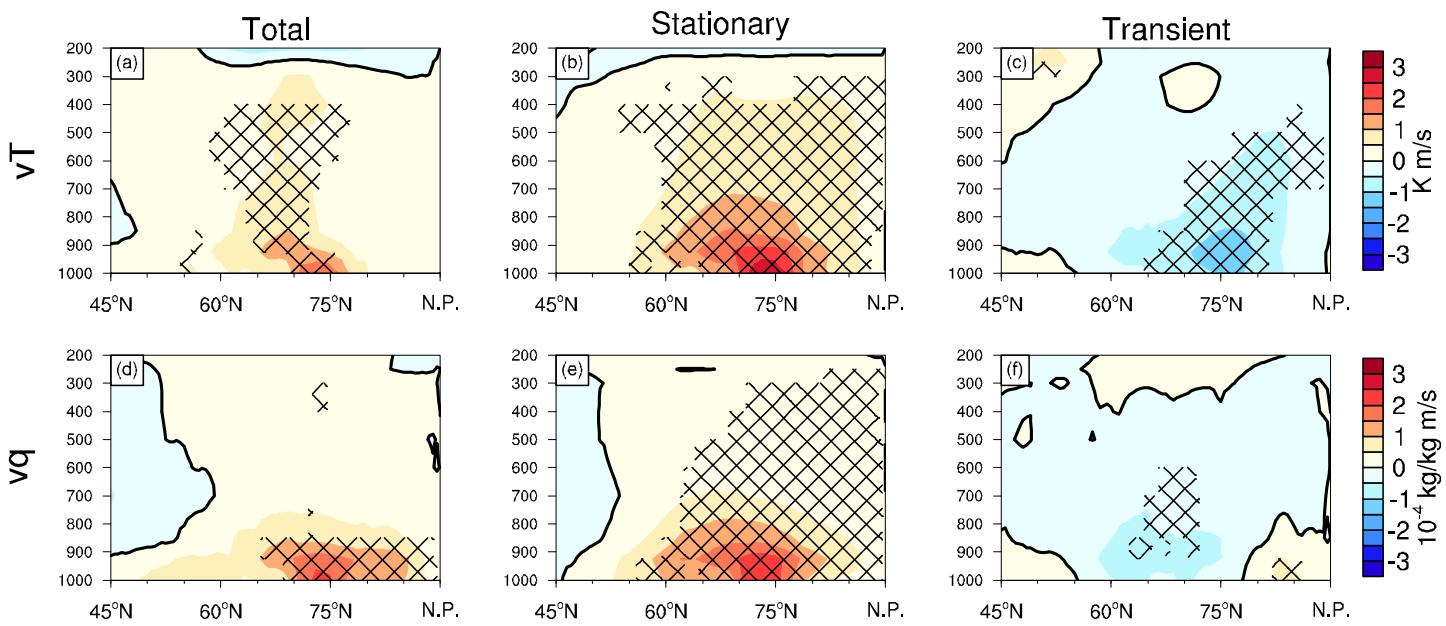

Figure 8. Wintertime zonally-averaged interannual anomalies of poleward heat $(\mathrm{K} \mathrm{m} / \mathrm{s}$, upper panels) and moisture $\left(10^{-4} \mathrm{~kg} / \mathrm{kg} \mathrm{m} / \mathrm{s}\right.$, lower panels) transports by total disturbances (left panels), stationary waves (central panels), and transient eddies (right panels), regressed upon a normalized Arctic warming index defined as the surface air temperature anomaly averaged over $75^{\circ} \sim 90^{\circ} \mathrm{N}$ and $0^{\circ} \sim 360^{\circ}$. The zero lines are shown

830 in bold black. The anomalies with values exceeding the $90 \%(\mathrm{p}<0.1)$ significance level

831 according to the Student's $t$-test are crossed. Note that the CFSR reanalysis dataset is 832 only used here. 

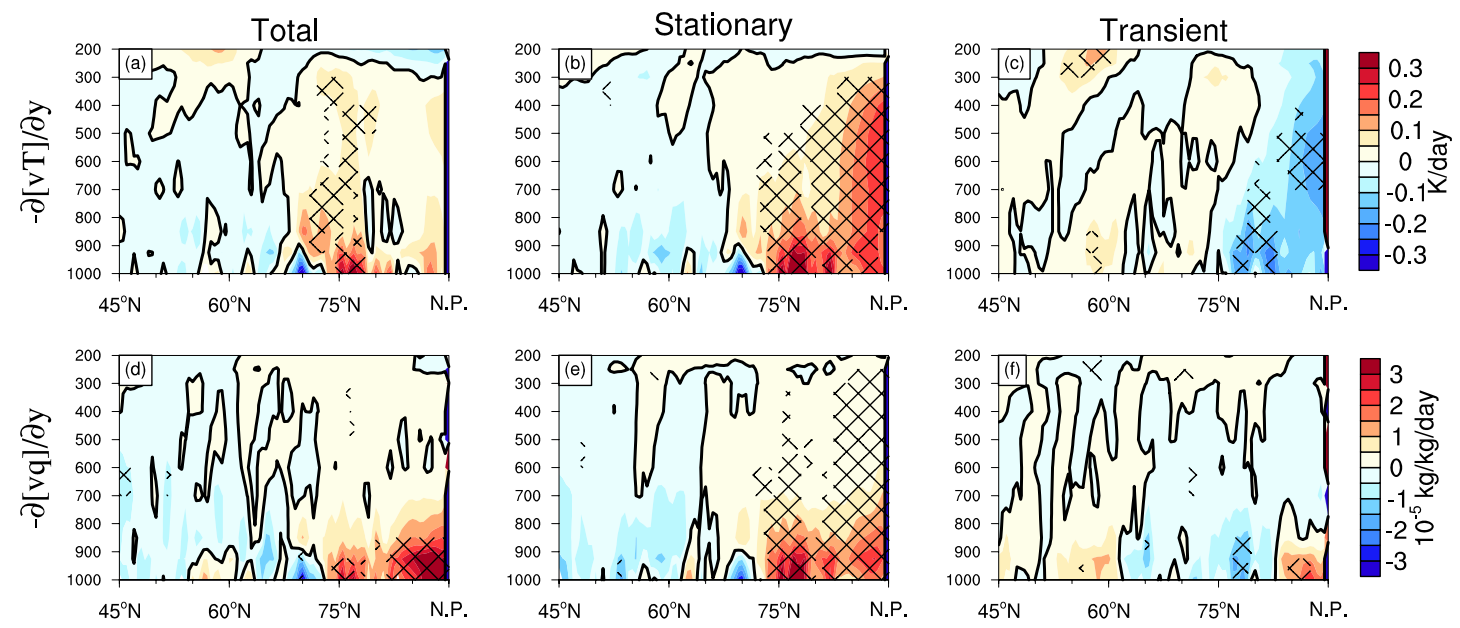

835 Figure 9. As in Fig. 8, but for the convergences of interannual anomalies of poleward 836 heat (upper panels) and moisture (lower panels) transports. 

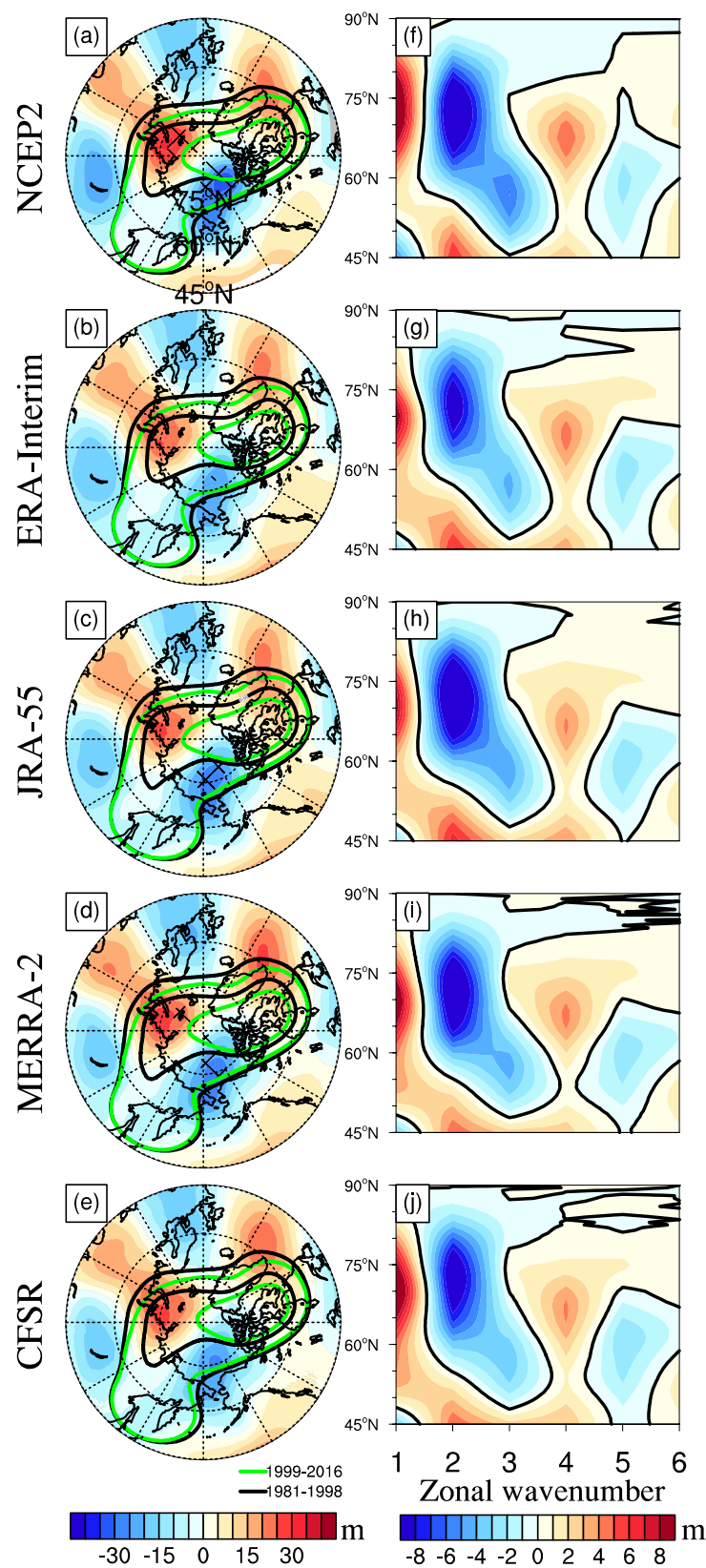

Figure 10. Decadal differences between 1999-2016 and 1981-1998 of the wintertime $500 \mathrm{hPa}$ geopotential height (gpm, left panels) and the amplitude of stationary waves

841 with zoanl wavenumber 1 6 (gpm, right panels), with five atmospheric reanalyses 842 (NCEP2, ERA-I, JRA-55, MERRA-2, and CFSR; from upper to lower panels). The 843 contours in left panels are $5100 \mathrm{~m}$ and $5180 \mathrm{~m}$ for 1999-2016 (black) and 1981-1998 844 (green), respectively. The bold black lines in right panels indicate the zero lines. 

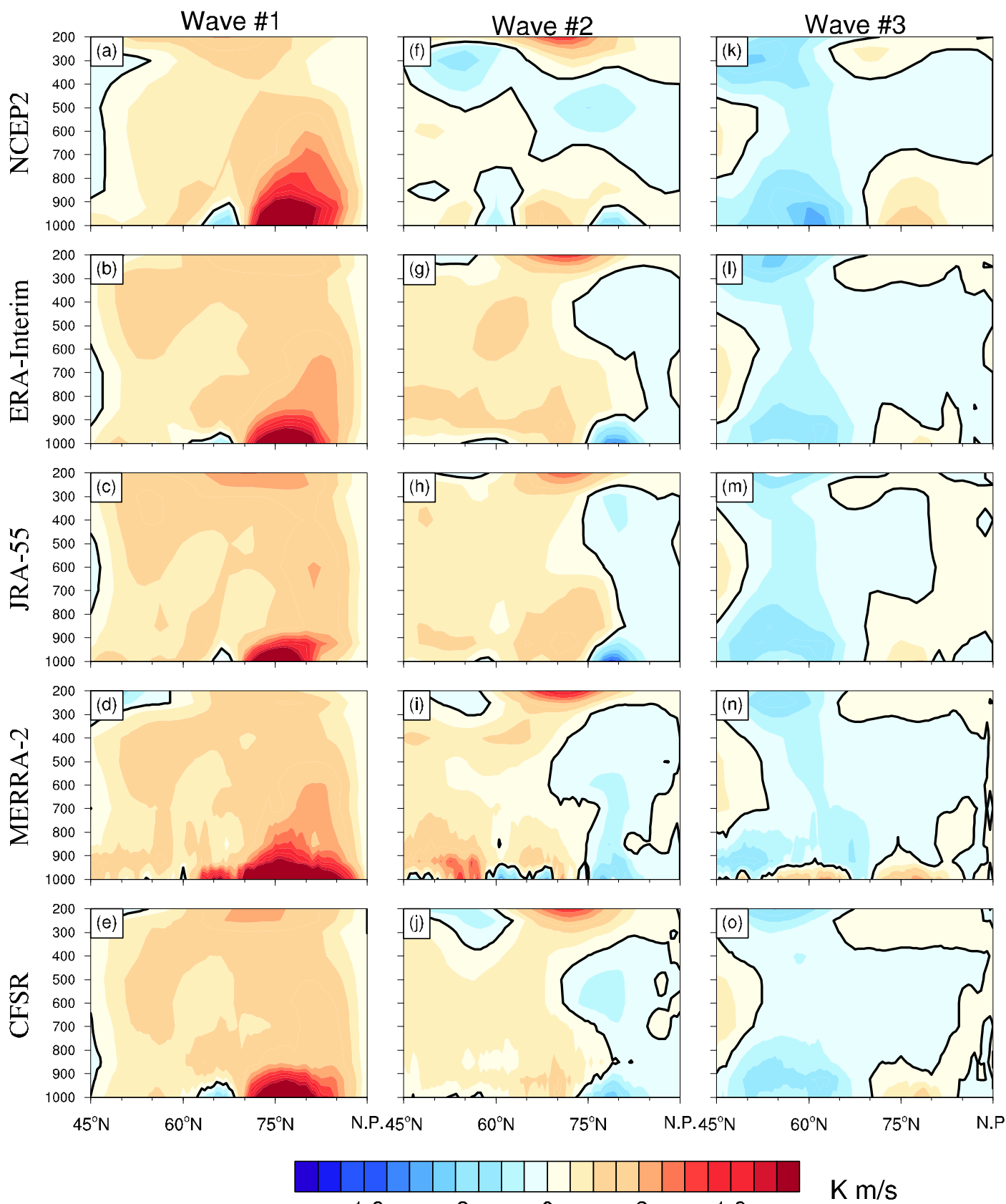

$-1.6$ $-.8$

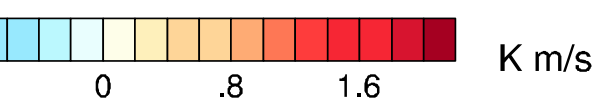

Figure 11. Decadal differences between 1999-2016 and 1981-1998 of wintertime zonally-averaged poleward heat transport by stationary wave component $(\mathrm{K} \mathrm{m} / \mathrm{s})$ of zonal wavenumber 1 (left panels), wavenumber 2 (central panels), and wavenumber 3 (right panels) with five atmospheric reanalyses (NCEP2, ERA-I, JRA-55, MERRA-2, and CFSR; from upper to lower panels). The zero lines are shown in bold black lines. 

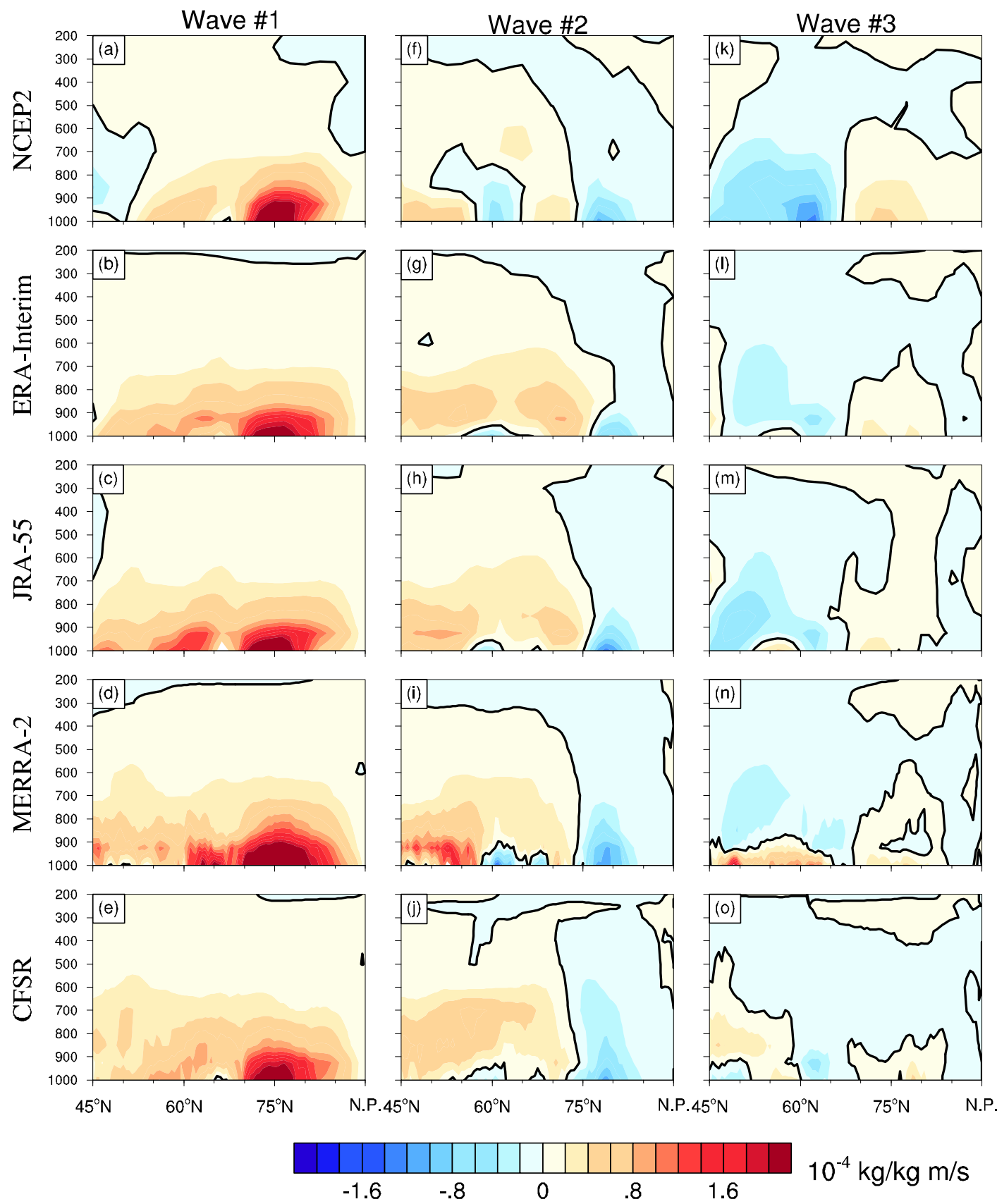

852 Figure 12. As in Fig. 11, but for the poleward moisture transport $\left(10^{-4} \mathrm{~kg} / \mathrm{kg} \mathrm{m} / \mathrm{s}\right)$. 

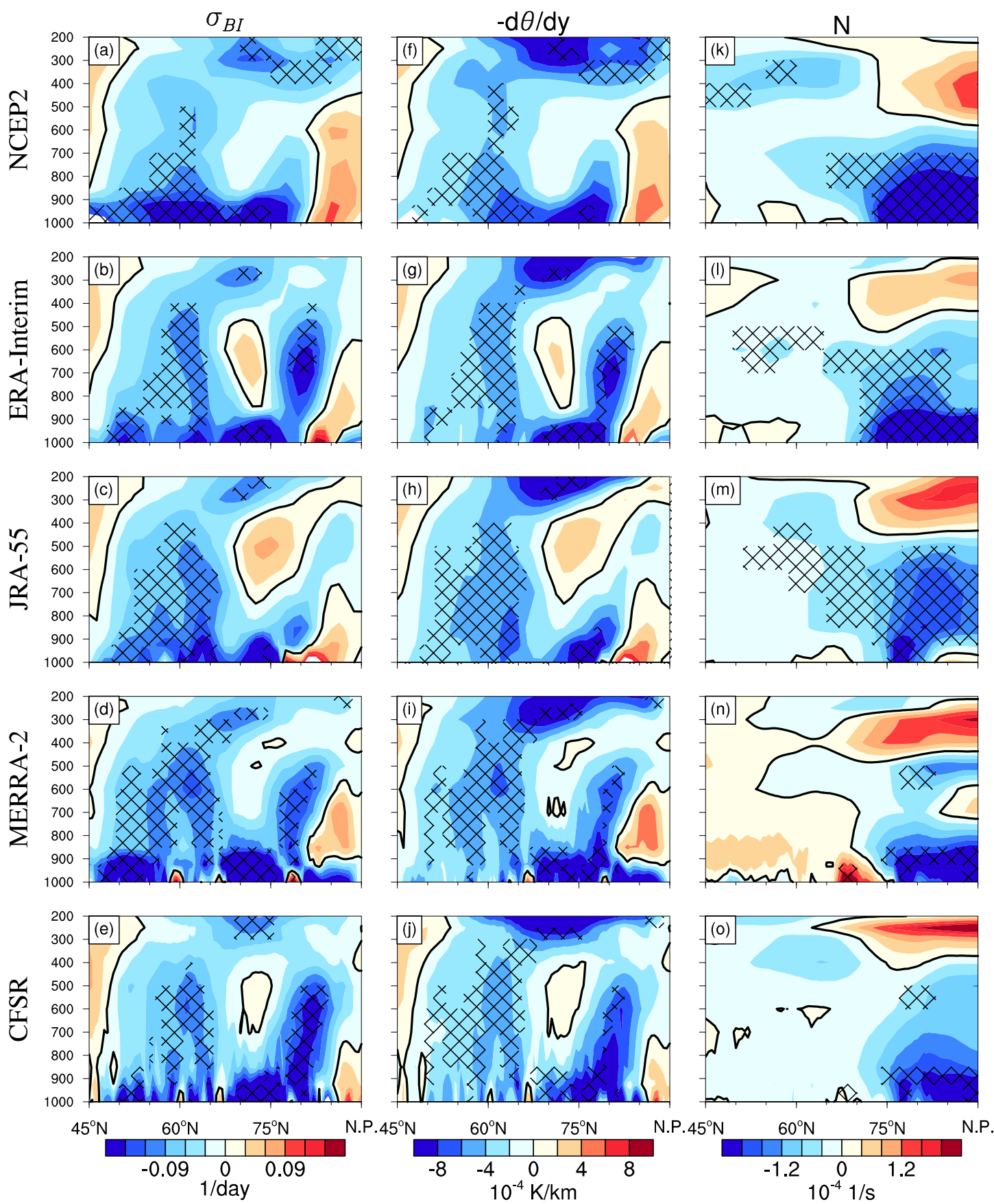

855 Figure 13. Decadal differences between 1999-2016 and 1981-1998 of wintertime

856 zonally-averaged maximum Eady growth rate (1/day) (left panels), meridional potential 857 temperature gradient $\left(10^{-4} \mathrm{~K} / \mathrm{km}\right)$ (central panels), and Brunt-Väis älä frequency $858\left(10^{-4} 1 / \mathrm{s}\right)$ (right panels) with five atmospheric reanalyses (NCEP2, ERA-I, JRA-55,

859 MERRA-2, and CFSR; from upper to lower panels). The zero lines are shown in bold 860 black. The differences with values exceeding the $90 \%(\mathrm{p}<0.1)$ significance level 861 according to the Student's $t$-test are crossed. 

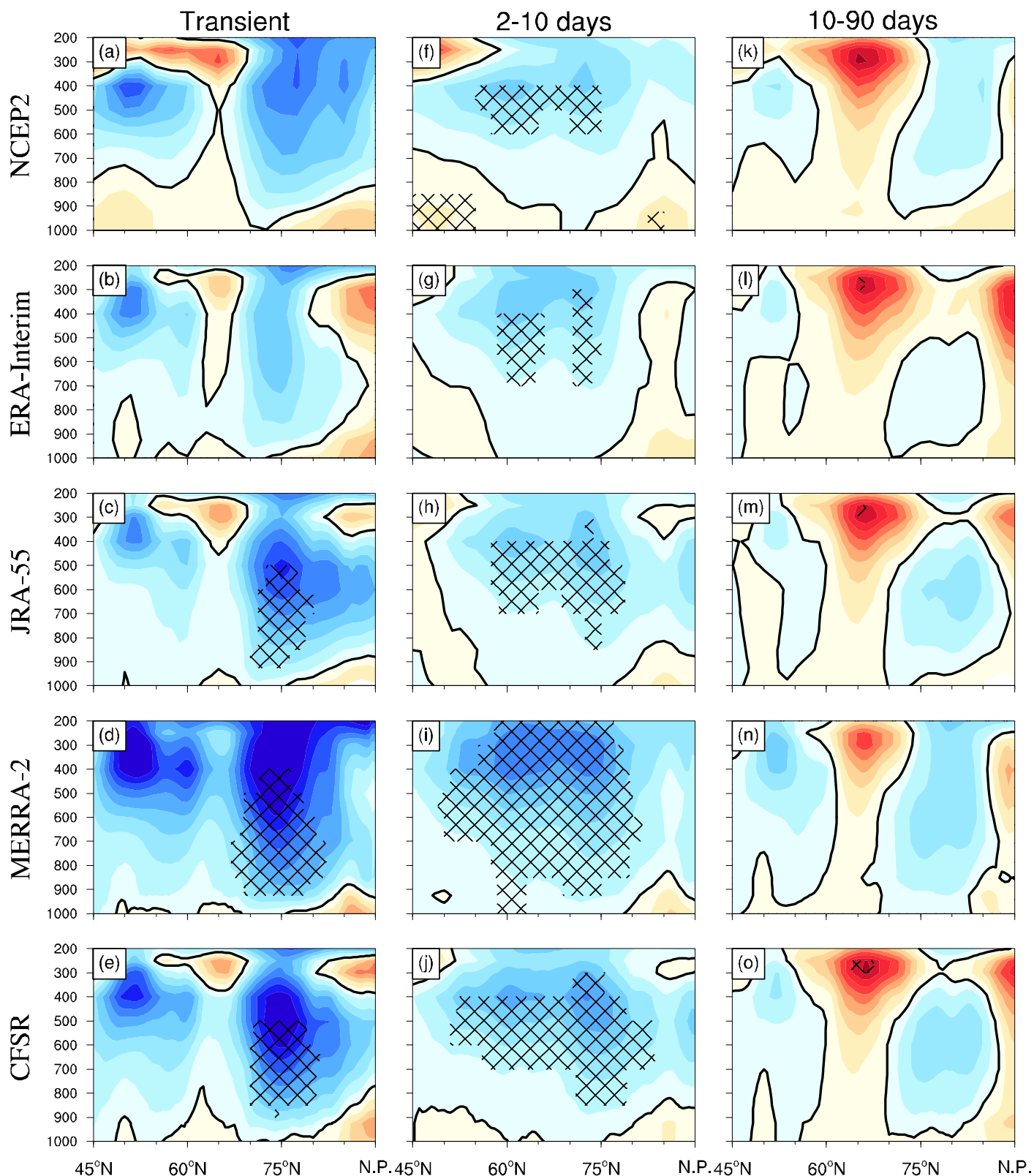

862

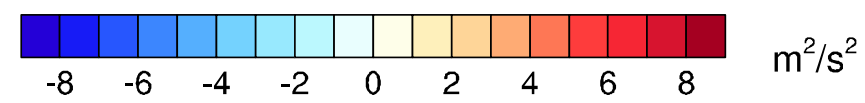

Figure 14. Decadal differences between 1999-2016 and 1981-1998 of wintertime zonally-averaged eddy kinetic energy $\left(\mathrm{m}^{2} / \mathrm{s}^{2}\right)$ of total transient eddies (left panels), high-frequency eddies with time-scale of 2-10 days (central panels), and low-frequency eddies with time-scale of 10-90 days (right panels), calculated with five atmospheric reanalyses (NCEP2, ERA-I, JRA-55, MERRA-2, and CFSR; from upper to lower panels). The zero lines are shown in bold black. The differences with values exceeding the $90 \%(\mathrm{p}<0.1)$ significance level according to the Student's $t$-test are crossed. 

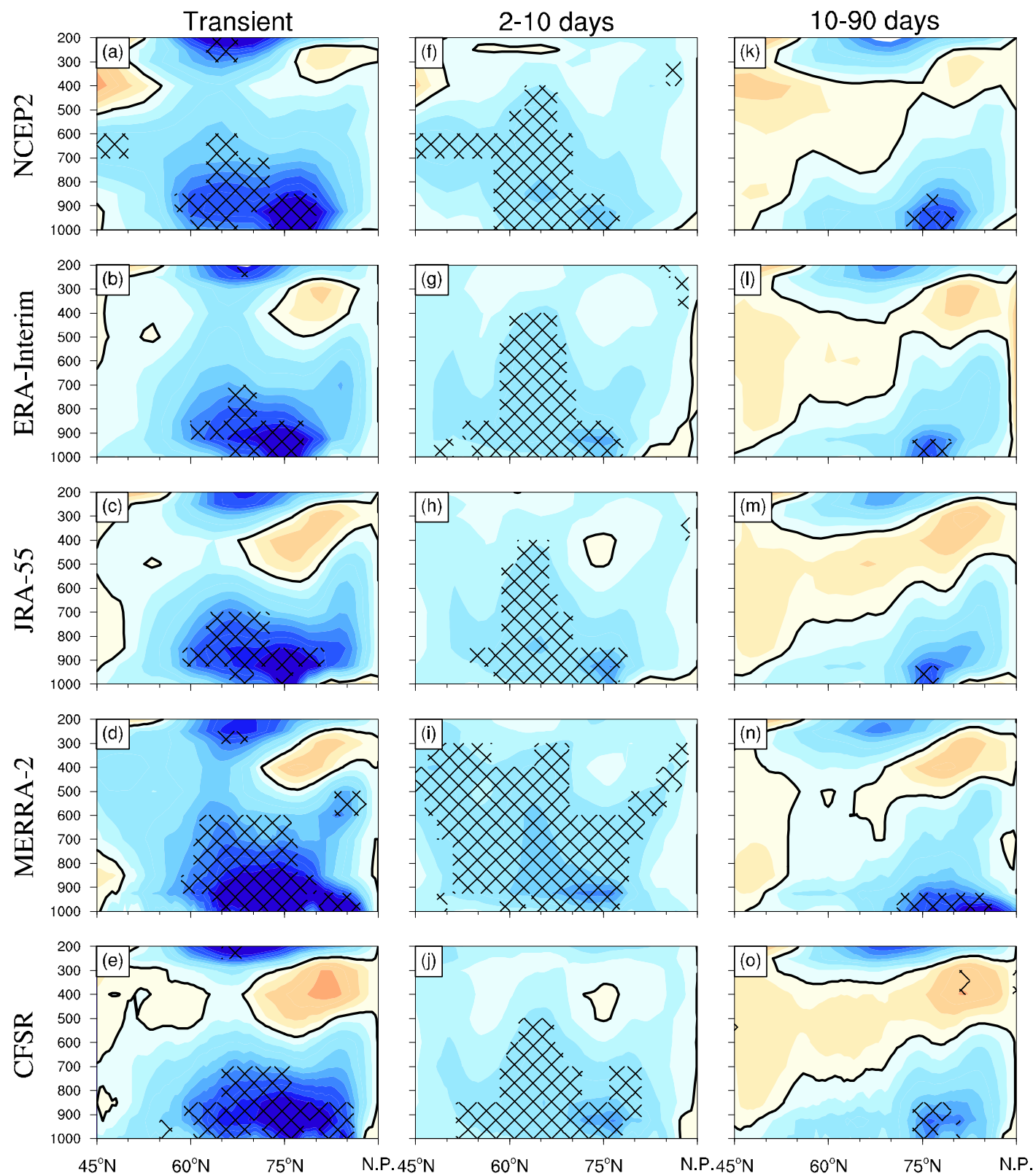

870

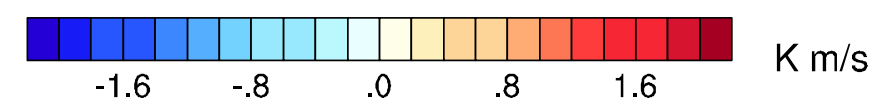

871 Figure 15. As in Fig. 14, but for the poleward heat transport $(\mathrm{K} \mathrm{m} / \mathrm{s})$. 

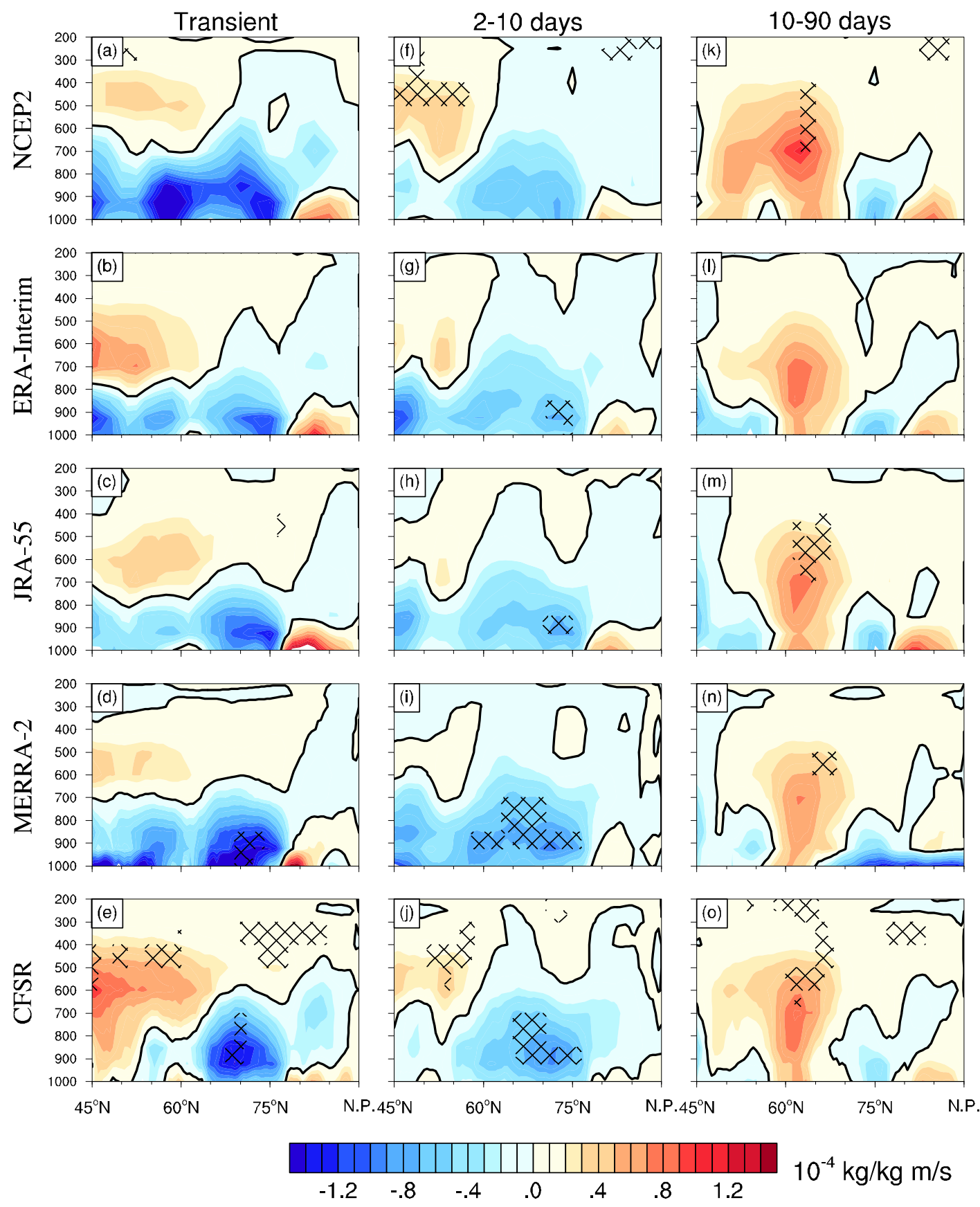

873 Figure 16. As in Fig. 14, but for the poleward moisture transport $\left(10^{-4} \mathrm{~kg} / \mathrm{kg} \mathrm{m} / \mathrm{s}\right)$. 


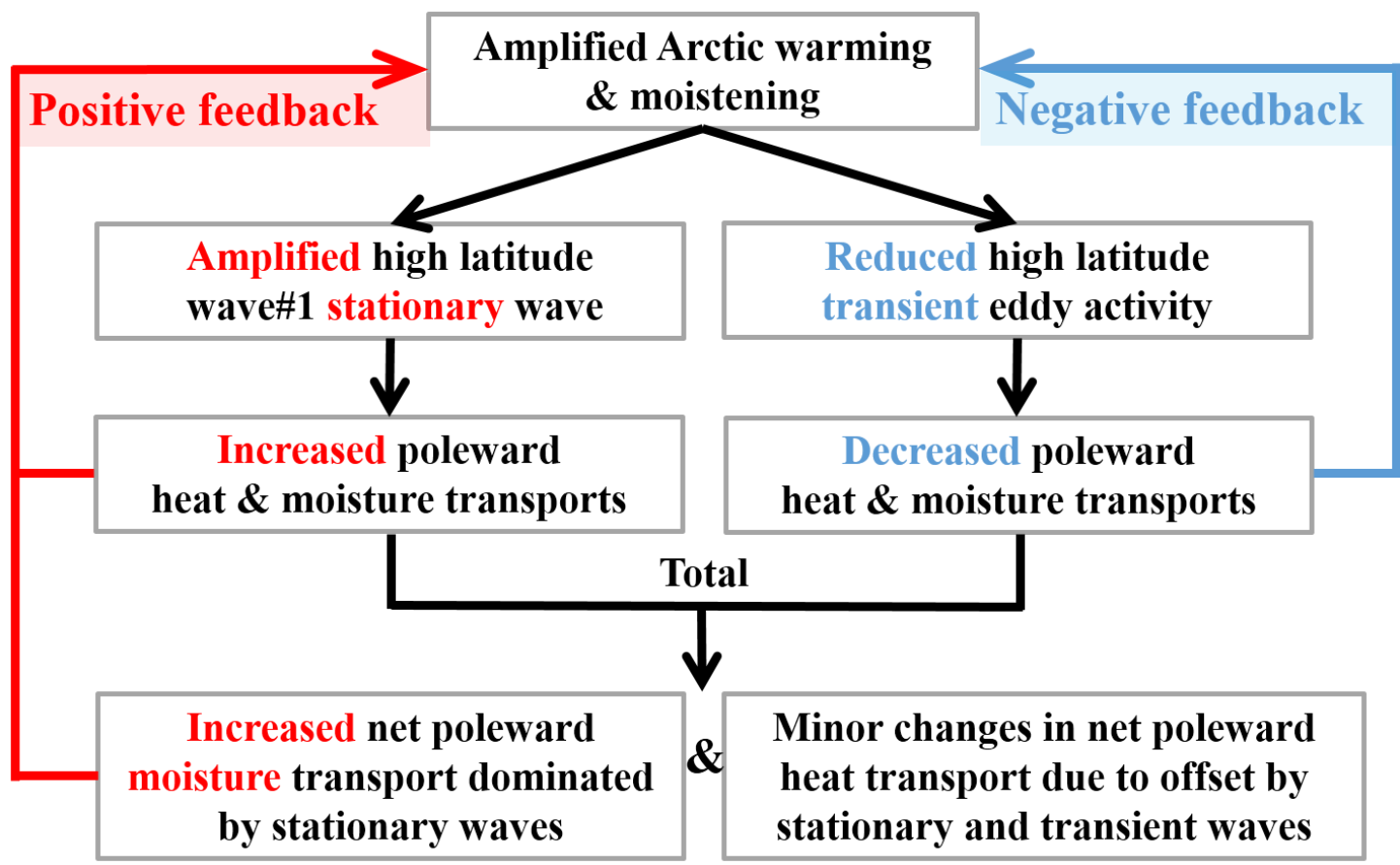

875 Figure 17. A schematic diagram for the impact of the amplified Arctic warming on the

876 high latitude poleward heat and moisture transports by stationary waves and transient 877 eddies and their possible feedbacks. 